\title{
Evaluation System on Haemodynamic Parameters for Stented Carotid Artery: Stent Pictorial Selection Method
}

\author{
Muhammad Sufyan Amir Paisal, Ishkrizat Taib*, Al Emran Ismail, Ahmad \\ Mubarak Tajul Arifin, Muhammad Faisal Mahmod
}

Faculty of Mechanical and Manufacturing Engineering (FKMP), Universiti Tun Hussein Onn Malaysia (UTHM), Batu Pahat, 86400, MALAYSIA

*Corresponding Author

DOI: https://doi.org/10.30880/ijie. 2019.11.01.024

Received 14 August 2018; Accepted 03 September 2019; Available online 30 April 2019

\begin{abstract}
Stent implantation is an alternative invasive technique for treating the narrowed artery or stenosis in carotid artery to restore blood to the brain. However, the restenosis process is usually observed after a few weeks of carotid angioplasty and stenting due to abnormal progression of atherosclerosis and thrombosis. Many studies reported that the activity of atherosclerosis and thrombosis is majorly influenced by the geometrical strut configuration. Thus, this study was carried out to determine the hemodynamic performance on different geometrical stent strut configurations based on numerical modelling and statistical analyses. In this study, there are six stent types with different geometry that resembles the existing stent, namely as Type I, Type II, Type III, Type IV, Type V and Type VI which are resembling to Exponent (Medtronic), Precise (Cordis), Protégé (ev3), Vivexx Carotid Stent (C. R. Bard), Zilver Stent (Cook) and Acculink (Abbott Vascular), respectively. The stent strut configurations were 3-D modelled and simulated in different physiological conditions; normal blood pressure (NBP), pre-hypertension (PH) and hypertension stage one (HS1) through computational fluid dynamic (CFD) method. The hemodynamic performance of stent was analyzed based on parameters namely time averaged wall shear stress (TAWSS), time averaged wall shear stress gradient (TAWSSG), oscillatory shear index (OSI), relative residence time (RRT) and flow separation parameter (FSP). Meanwhile, Pictorial Selection Method was used to evaluate the best hemodynamic stent performance based on a scoring system. From observation, stent Type II was seen to show the highest score for TAWSS, which about 3.44 regardless of any physiological conditions. For TAWSSG, the lowest score was observed for Type V stent with 0.36. Furthermore, Type VI stent displayed the highest score for OSI while Type IV has the lowest score for FSP with 3.09 and 1.23, respectively. On the other hand, RRT was seen varying according to the physiological condition where the highest score in NBP condition was achieved by Type I while PH and HS1 condition was achieved by Type VI. In conclusion, Type VI has the best stent performance, whereas Type IV has the worst stent performance regarding the scoring system based on hemodynamic parameters. Further, Type I, Type II, Type III and Type V stents showed moderate hemodynamic performances for all physiological conditions.
\end{abstract}

Keywords: carotid artery, stent, hemodynamic parameter, evaluation

\section{Introduction}

Treatment of stenosed artery or arterial blockage by using medical device called as stent has been widely used due to its invasive technique. The cardiovascular disease of stenosis occurs due to the build-up atherosclerotic plaque and thrombosis formation. However, re-blockage or restenosis of the artery tend to happen again after 30 days of stent implantation where the reported cause of the complication is due to the geometrical stent strut configuration [1]. Within five years after stent implantation, a moderate restenosis with $50 \%$ of an arterial diameter reduced is reported to have 
an occurrence rate about $40.7 \%$ while a severe restenosis with $70 \%$ of the arterial diameter reduced has an occurrence rate about $10.6 \%$ [2]. Kastrati et al. found that stent design is among the strongest factors of restenosis incidence ranging from $20.0 \%$ to $50.3 \%$ [3]. The restenosis development occurs due to the misaligned direction of blood flow develops into a flow recirculation near the stented region of the artery. Since this study is focusing on carotid artery, an approximately 30 days after stent implantation, the recirculated blood flow near the stented region undergoes restenosis that restricts the blood supply to the face and brain. In the end, several complications are occurred such as minor stroke, major stroke, transient ischemic attack and even death as shown in Table $1[1,4,5]$. Table 1 shows a data of postprocedural event rates of the stated complications on each existing stent devices such as Precise, Protégé, Acculink and Exponent. The geometries of the existing devices can be seen in Table 2 with an addition of Vivexx Carotid Stent and Zilver Stent [6-11]. Furthermore, hypertension is one of the risk factors that accelerate the stenosis development [12]. A population based study by Woo et al. in 2017 reported that the hypertension is the highest risk factor of stenosis about $48.6 \%$ for male and $51.3 \%$ for female, as compared to diabetes mellitus, hyperlipidemia and smoking [13-50].

Table 1 - Post-procedural event rates for each carotid stent [1].

\begin{tabular}{ccccc}
\hline Device & Death $(\boldsymbol{\%})$ & Major stroke $(\boldsymbol{\%})$ & Minor stroke $(\boldsymbol{\%})$ & TIA $(\boldsymbol{\%})$ \\
\hline Precise & 0.7 & 0.3 & 0.7 & 2.4 \\
Protege & 0.0 & 0.0 & 1.5 & 1.5 \\
Acculink & 0.0 & 0.5 & 0.7 & 2.9 \\
Exponent & 0.0 & 0.0 & 2.9 & 8.8 \\
\hline
\end{tabular}

Table 2 - Existing geometrical stent configurations.

\begin{tabular}{|c|c|c|c|c|c|c|}
\hline $\begin{array}{c}\text { Stent name } \\
\text { (manufacturer) }\end{array}$ & $\begin{array}{c}\text { Exponent } \\
\text { (Medtronic) } \\
{[6]}\end{array}$ & $\begin{array}{c}\text { Precise } \\
\text { (Cordis) [6- } \\
\text { 8] }\end{array}$ & $\begin{array}{c}\text { Protégé } \\
(\mathrm{ev3})[7,8]\end{array}$ & $\begin{array}{c}\text { Vivexx } \\
\text { Carotid Stent } \\
\text { (C. R. Bard) } \\
{[7,8]}\end{array}$ & $\begin{array}{c}\text { Zilver Stent } \\
(\text { Cook) [9] }\end{array}$ & $\begin{array}{l}\text { Acculink } \\
\text { (Abbott } \\
\text { Vascular) } \\
{[10,11]}\end{array}$ \\
\hline Stent geometry & (mis & Wy & WW & N & (n) & (n) \\
\hline
\end{tabular}

The restenosis development of carotid artery implanted with different geometrical stent strut configuration can be invasively analysed and predicted with the current numerical simulation technology via computational fluid dynamic (CFD) method. The use of CFD method has emerged as a powerful tool to predict blood flow patterns in stented artery with the development of electronic computers before undergoing the in vivo study. Thus, the restenosis due to misalignment of blood flow direction causing recirculation and vortex near the stent strut can be numerically detected [14]. Additionally, several haemodynamic variables are very useful in predicting the restenosis of blood flow comprises time averaged wall shear stress (TAWSS), time averaged wall shear stress gradient (TAWSSG), oscillatory shear index (OSI), relative residence time (RRT) and flow separation parameter (FSP) [15]. Based on previous studies, these haemodynamic parameters have specific threshold or range of values to indicate the activity of atherosclerosis and thrombosis that reflect the restenosis development [16-21, 50-70].

From each haemodynamic variables, a statistical distribution is obtained to evaluate the best stent performance based on the threshold of acceptable values determined by previous studies [22, 23]. The stent performance evaluation known as Stent Pictorial Selection Method was used in this study adapted from the Concept Selection Method by Ulrich et al., which originally evaluates the concept design of a product [24]. The evaluation method is able to detect the best stent strut configuration with the lowest score of restenosis development. Thus, this study aimed at statistically evaluating the haemodynamic performance of different stent geometrical designs in different physiological conditions especially normotensive and hypertensive blood flow. Therefore, the blood flow physiological conditions are grouped 
into three categories at increasing blood pressure order which are normal blood pressure (NBP), pre-hypertension (PH) and hypertension stage one (HS1).

\section{Methodology}

The evaluation system of Stent Pictorial Selection Method is started by modeling a simplified and stented carotid artery using a computer-aided design (CAD) commercial software SOLIDWORKS (Dassault Systèmes SolidWorks Corporation, Waltham, Massachusetts, United States). The developed models are then simulated for their performance of haemodynamic parameters that consisting of TAWSS, TAWSSG, OSI, RRT and FSP using CFD commercial software ANSYS FLUENT (Canonsburg, Pennsylvania, United States). The simulated haemodynamic performances are analysed statistically and evaluated based on the implemented system using numerical computation software MATLAB (Mathworks, Natick, Massachusetts, United States) in order to find the best geometry of the stent strut configuration.

\subsection{Geometries of the Resembled Stent Strut Configuration}

There are six types of stent for the current study which resembled the existing stent strut configuration. As shown in Figure 1, Type I resembled Exponent (Medtronic), Type II resembled Precise (Cordis), Type III resembled Protégé (ev3), Type IV resembled Vivexx Carotid Stent (C. R. Bard), Type V resembled Zilver Stent (Cook) and Type VI resembled Acculink (Abbott Vascular) [6-11]. The modeled stents have a dimension of length $\left(l_{S}\right)$, thickness $\left(h_{S}\right)$ and outer radius $\left(r_{o}\right)$ which equivalents to $20 \mathrm{~mm}, 0.2 \mathrm{~mm}$ and $3.25 \mathrm{~mm}$, respectively. The outer radius of stent is a little bit oversized than the arterial diameter as suggested by Rabe et al. (2009) for the step-by-step guideline of carotid stenting [25]. The carotid artery is drawn as simplified model for a clear vision on the effect by the haemodynamic parameters. Thus, arterial diameter of common carotid artery (CCA) where the stent deployed is $3.2 \mathrm{~mm}$. The location of the stent is placed $33.5 \mathrm{~mm}$ from the bottom of the CCA region as shown in Figure 2.

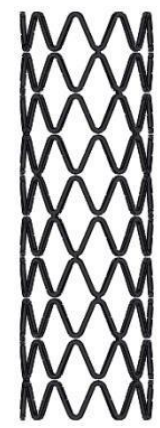

(a)

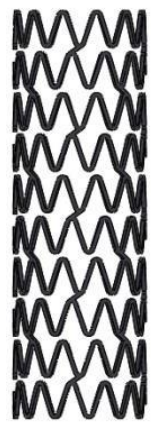

(b)

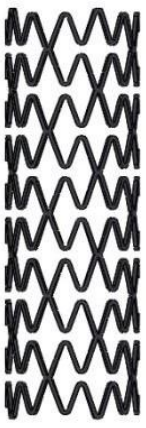

(c)

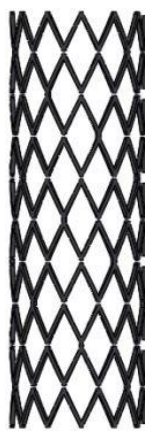

(d)

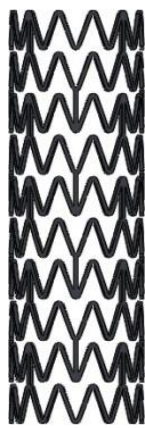

(e)

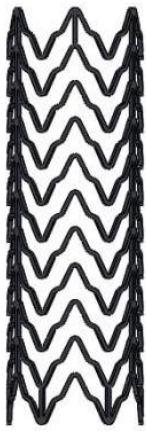

(f)

Fig. 1 - Geometrical shape of each stent strut configuration for (a) Type I, (b) Type II, (b) Type III, (c) Type IV, (d) Type V and (e) Type VI that resembled to the existing stent strut configurations [6-11].

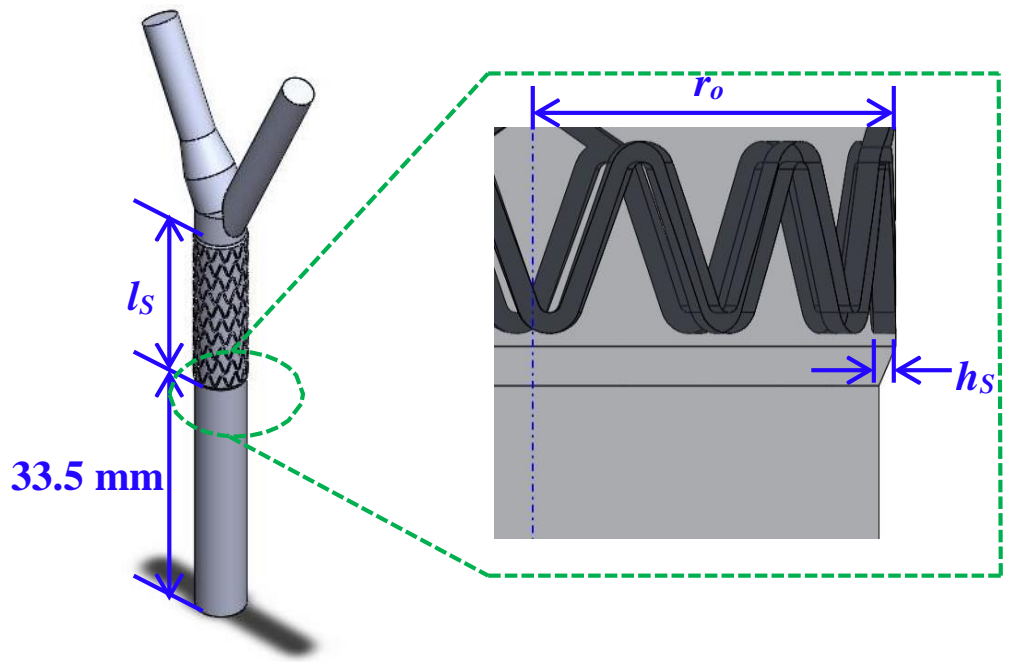

Fig. 2 - Geometrical shape of each stent strut configuration (dark grey region shows stent and light grey region shows artery model). 


\subsection{Physiological Flow Condition of Blood in Carotid Artery}

Normotensive and hypertensive carotid artery have different pattern of blood flow waveform. It is proven by a previous study done by Azhim et al. in 2013 where the velocity waveform of NBP, PH and HS1 are differ each other at increasing blood pressure as shown in Figure 3. Specifically, systolic blood pressure (SBP)/diastolic blood pressure (DBP) for NBP, PH and HS1 is $117 / 71 \mathrm{mmHg}, 124 / 81 \mathrm{mmHg}$ and $148 / 96 \mathrm{mmHg}$, respectively [26]. Thus, the physiological flow condition data by Azhim et al. is used for obtaining the haemodynamic effect due to the increase of blood pressure in the CFD simulation process.

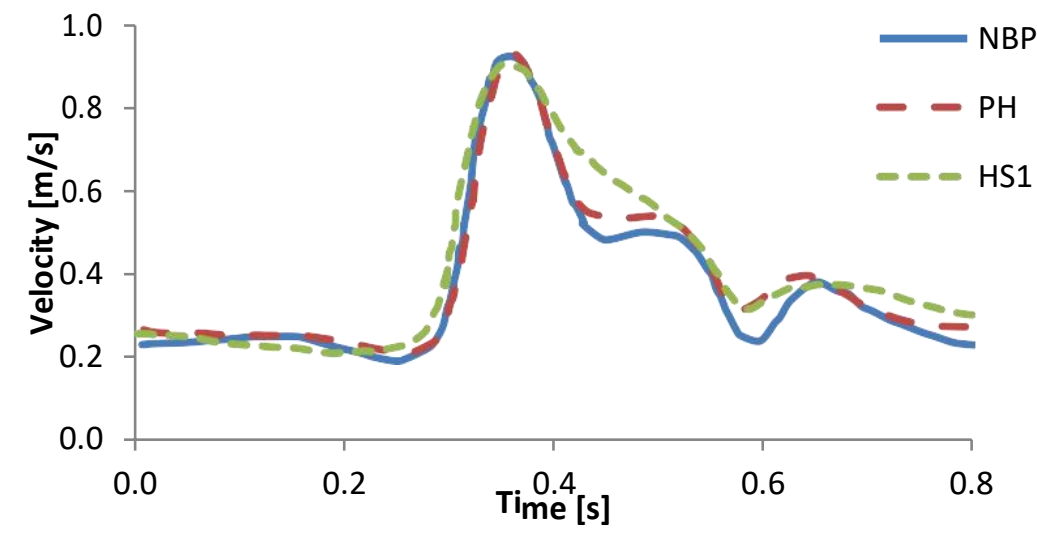

Fig. 3 - Velocity waveform of carotid artery at different physiological flow condition.

\subsection{Haemodynamic Parameters of Stented Carotid Artery}

There are several haemodynamic variables used to evaluate the performance of the commercial stent. One of the commonly analysed haeomdynamic performances, wall shear stress (WSS), is a drag exerted by flowing bloo ${ }_{\mathrm{r}} \mathrm{d}$ on the arterial wall [27] that can be measured as in the equation (1) where $n$ is a normal vector to a wall surface and $\tau_{i j}$ is the fluid viscous stress tensor [15].

$$
\stackrel{\mathrm{r}}{\tau}=\stackrel{\mathrm{r}}{{ }_{n}} \underset{\tau}{\mathrm{r}}
$$

The range of WSS for normal artery is from 10 to 70 dyne $/ \mathrm{cm}^{2}$. A higher value of WSS than 70 dyne $/ \mathrm{cm}^{2}$ indicates a high shear thrombosis of the arterial wall while WSS between -4 and $4 \mathrm{dyne} / \mathrm{cm}^{2}$ shows a region prone to atherosclerosis formation $[16,28]$. Since this study is a transient case, WSS was time averaged to get the mean value representing WSS for each cardiac cycle of heartbeat. Thus, TAWSS was calculated using equation (2) where $T$ is the duration of one cardiac cycle and $d t$ is the increment of time [28]. Therefore, TAWSS based on research by Malek et al. (1999) was split into three variables, which are TAWSS high, TAWSS $_{\text {norm }}$ and TAWSS Tow $_{\text {l6]. TAWSS }}$ Tigh is $_{\text {WSS }}$ higher than $7 \mathrm{~Pa}$, TAWSS $_{\text {norm }}$ is WSS between 1 and $7 \mathrm{~Pa}$, while TAWSS low $_{\text {is }}$ WSS between -0.4 and $0.4 \mathrm{~Pa}$.

$$
\begin{gathered}
1^{T} \mathrm{r} \\
T \int_{0}\left|\tau_{w}\right| d t
\end{gathered}
$$

The gradient of WSS also can be analysed, where the wall shear stress gradient (WSSG) indicates the formation of new layer of endothelial cells due to different magnitudes of WSS. The desired WSSG value is equal to and less than $5000 \mathrm{~Pa} / \mathrm{m}$. Values higher than that could lead to proliferation of endothelial cells and arterial stenosis [15]. The computation of WSSG involves WSS derivatives in two directions, which are blood flow direction $(\alpha)$ and normal to the direction $(\beta)$ as stated in equation (8) [29]. Since this study is a pulsatile flow, WSSG was computed as TAWSSG as shown in equation (4) [15].

$$
\mathrm{WSSG}=\sqrt{\left(\begin{array}{l}
\partial \tau)^{2}+\left(\begin{array}{l}
\partial \tau \\
\partial \alpha
\end{array}\right)^{2} \\
\partial \beta
\end{array}\right)^{2}}
$$


$1^{T}$ uunuuuur
TAWSSG $=\frac{T}{T} \int_{0}^{\mid}|\mathrm{WSSG}| d t$

Besides, OSI provides an index describing the shear stress that acts in the directions other than that of the temporal mean shear stress vector [30]. The range of OSI for stented artery is from 0 to 0.5 . The region with high OSI is predicted to have a high risk of atherosclerosis activity. Since the arterial surfaces with OSI higher than 0.3 are prone to atherosclerosis, the desired value of OSI for better stent performance is from 0.0 to 0.2 [28]. The formulation of the OSI was shown as follows:

$$
\text { OSI }=\frac{1 \mid}{2}\left|\frac{\left|\int_{0}^{T}{ }_{w} d t\right|}{1-\int_{0}^{T}\left|\tau_{w}\right| d t}\right|
$$

By applying OSI and TAWSS as another scalar-valued quantity called as RRT, the parameter is able to indirectly characterise the time amount of contacting atherogenic particles with the arterial wall. Longer time of contact between atherogenic particles and the arterial wall could cause a high prediction on atherosclerosis formation. The atherogenic activity can be seen through RRT higher than $10 \mathrm{~Pa}^{-1}$ [28]. Therefore, the optimum value of RRT for stented haemodynamic model should be less than or equal to $10 \mathrm{~Pa}^{-1}$. Thus, RRT was defined as follows [23]:

$$
\mathrm{RRT}=\frac{1}{(1-2 \times \mathrm{OSI}) \times \mathrm{TAWSS}}
$$

Lastly, FSP $(\psi)$ is a fraction of time in one cardiac cycle where a flow at some point is separated from the mainstream flow. A higher FSP value in the stented artery could lead to neo-intimal hyperplasia. The FSP value can be obtained using equation (7) where $T s$ is the amount of time that flow is separated and $T$ is the duration of one cardiac cycle [15]. Alternatively, FSP is a change of axial WSS direction induced by either forward or reverse mainstream flow in the specified cardiac cycle. FSP is ranged from 0 to 1 where 0 represents no flow separation while 1 represents flow recirculation. In evaluating the best stent performance, FSP was split into $\mathrm{FSP}_{\text {low }}$ and $\mathrm{FSP}_{\text {high }}$. FSP low is FSP lower than 0.1 indicating the mainstream flow reattachment. $\mathrm{FSP}_{\text {high }}$ is FSP higher than 0.5 representing the flow recirculation [21]. However, none of the previous studies indicated the FSP distribution between 0.1 and 0.5 as neither reattachment nor separation. Therefore, FSP between 0.1 and 0.5 are not focused.

$$
\psi=\frac{T_{s}}{T}
$$

\subsection{Statistical Properties for Stent Performance Evaluation}

The stents performance is statistically evaluated utilising Stent Pictorial Selection Method. Prior to the evaluation process of the stent, there are several statistical parameters for each haemodynamic characteristic that need to be analysed, which are area-averaged mean $(\mu)$, standard deviation $(\sigma)$ and kurtosis $(K)$. The parameters are obtained using equations (8), (9) and (10), where $A_{i}$ is the surface area of face $i$ and $\varphi_{i}$ is the haemodynamic characteristics at face $i$ [23].

$$
\begin{aligned}
& \mu=\frac{\sum_{i=0}^{e}\left(A_{i} \times \varphi_{i}\right)}{\sum_{i=0}^{e} A} \\
& \sigma=\sqrt{\left.\frac{\sum_{j=0}^{e}\left[A_{i} \times\left(\varphi_{i}-\mu\right)^{2}\right]}{\sum_{i=0}^{e} A_{i}}\right]}
\end{aligned}
$$




$$
\left.K=\frac{\sum_{i=0}^{e}\left\lceil(A) \times(\varphi-\mu)^{4}\right\rceil}{\sum_{i=0}^{e} i_{i}^{i}\left(A \times \sigma^{4}\right)}\right\rfloor
$$

In evaluating the best stent performance, the statistical properties of TAWSS is desired to have high mean value while TAWSSG, OSI, RRT and FSP favour a low mean value. Thus, the haemodynamic parameters favour a high value of kurtosis indicating data distribution is weighted to the mean value. By assuming the mean value of each study case is in the allowable range, the high kurtosis indicates low risk for restenosis complication. For further information, related papers can be found [50-107].

\subsection{Stent Pictorial Selection Method}

Stent Pictorial Selection Method is originally based on Concept Selection Method introduced by Ultrich et al. to evaluate product design concept [24]. By combining the allowable and unacceptable range of haemodynamic data distributions, this method is suitable to evaluate the stent strut configuration. The method consists of three main stages, which are screening, rating and scoring.

The screening stage depends on percentage of data distribution for luminal surface area covered by each specific blood flow characteristic $\left(\varphi_{\text {perc }}\right)$. The evaluation in this stage is relative to a reference data that based on the simulation of unstented normal physiological condition of carotid artery. The haemodynamic parameters of the reference data $\left(\varphi_{\text {ref }}\right)$ are as seen in Table 3. The reference data has the most excellent haemodynamic performance due to low percentage of

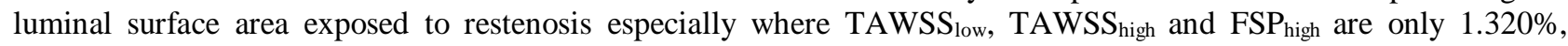
$2.045 \%$ and $6.368 \%$, respectively.

Table 3 - Reference data of luminal surface area covered by haemodynamic specific parameter.

\begin{tabular}{cc}
\hline $\begin{array}{c}\text { Haemodynamic } \\
\text { parameter }\end{array}$ & $\begin{array}{c}\text { Reference luminal } \\
\text { surface area, } \boldsymbol{\varphi}_{\text {ref }}(\boldsymbol{\%})\end{array}$ \\
\hline TAWSS $_{\text {low }}$ & 1.320 \\
TAWSS $_{\text {norm }}$ & 93.654 \\
TAWSS $_{\text {high }}$ & 2.045 \\
TAWSSG & 98.028 \\
OSI & 99.947 \\
RRT & 99.869 \\
FSP $_{\text {low }}$ & 82.272 \\
FSP $_{\text {high }}$ & $\underline{6.368}$ \\
\hline
\end{tabular}

If $\varphi_{\text {perc }}$ is better than $\varphi_{\text {ref, }}$ a relative score for the parameter is assigned as ' + ' and if $\varphi_{\text {perc }}$ is worse than $\varphi_{\text {ref }}$, a relative score for the parameter is assigned as '-'. Assignation of relative score was done for all type of stents and blood conditions as seen in Table 4. Thus, a net score of total '+' minus total ' - ' is calculated across the stent types and haemodynamic parameters to see a rough evaluation on stent performance.

Table 4 - Screening stage matrix.

\begin{tabular}{ccccccc}
\hline Stent & $\begin{array}{c}\text { Parameter } \\
\mathbf{A}, \boldsymbol{\varphi}_{\text {perc }, \boldsymbol{A}}\end{array}$ & $\begin{array}{c}\text { Parameter } \\
\mathbf{B}, \boldsymbol{\varphi}_{\text {perc }, \boldsymbol{B}}\end{array}$ & $\begin{array}{c}\text { Parameter } \\
\mathbf{C}, \boldsymbol{\varphi}_{\text {perc }, \boldsymbol{C}}\end{array}$ & $\begin{array}{c}\text { Relative } \\
\text { score A }\end{array}$ & $\begin{array}{c}\text { Relative } \\
\text { score B }\end{array}$ & $\begin{array}{c}\text { Relative } \\
\text { score C }\end{array}$ \\
\hline Type $\lambda$ & $\mathrm{A}_{\lambda}$ & $\mathrm{B}_{\lambda}$ & $\mathrm{C}_{\lambda}$ & - & - & + \\
Type $\phi$ & $\mathrm{A}_{\phi}$ & $\mathrm{B}_{\phi}$ & $\mathrm{C}_{\phi}$ & - & + & + \\
\hline
\end{tabular}

Next stage is the rating of stent performance values $\varphi_{\text {perc }}, \mu$ and $K$ for each stents. Since the present study has six stent strut configurations for each physiological condition, the stent performances are classified into six categories for the rating process. Thus, the rates of stent from 1 to 6 indicate from the worst to the best stent performance as seen in Table 5 and Table 6. 
Table 5 - Rate of relative stent performance.

\begin{tabular}{cc}
\hline Relative stent performance & Rating \\
\hline The worst stent performance & 1 \\
Very bad stent performance & 2 \\
Mildly bad stent performance & 3 \\
Mildly good stent performance & 4 \\
Very high stent performance & 5 \\
The best stent performance & $\underline{6}$ \\
\hline
\end{tabular}

Table 6 - Rating stage matrix.

\begin{tabular}{ccccccc}
\hline Stent & $\begin{array}{c}\text { Parameter } \\
\mathbf{A}, \boldsymbol{\varphi}_{\text {perc }, \boldsymbol{A}}\end{array}$ & Rating A & $\begin{array}{c}\text { Parameter } \\
\mathbf{B}, \boldsymbol{\varphi}_{\text {perc }, \boldsymbol{B}}\end{array}$ & Rating B & $\begin{array}{c}\text { Parameter } \\
\mathbf{C}, \boldsymbol{\varphi}_{\text {perc }, \boldsymbol{C}}\end{array}$ & Rating C \\
\hline Type $\lambda$ & $\mathrm{A}_{\lambda}$ & $r_{\mathrm{A}, \lambda}$ & $\mathrm{B}_{\lambda}$ & $r_{\mathrm{B}, \lambda}$ & $\mathrm{C}_{\lambda}$ & $r_{\mathrm{C}, \lambda}$ \\
Type $\phi$ & $\mathrm{A}_{\phi}$ & $r_{\mathrm{A}, \phi}$ & $\mathrm{B}_{\phi}$ & $r_{\mathrm{B}, \phi}$ & $\mathrm{C}_{\phi}$ & $r_{\mathrm{C}, \phi}$ \\
\hline
\end{tabular}

Last stage for this method is scoring where the weighted score summation $\left(S_{j}\right)$ of each stent as shown in equation (11) plays the main role in ranking the performance where $r_{i, j}$ is the raw rating of stent $j$ for stent performance $i, w_{i}$ is the weightage for stent performance $i$ and $n$ is the number of stent performances.

$$
S_{j}=\sum_{i=1}^{n} r_{i, j} w_{i}
$$

The weightage $(w)$ consideration of the haemodynamic parameters are sorted into of how important of them based on previous study as shown in Table 7, which called as influence level. Thus, the haemodynamic parameters are sorted from the top place with the highest influence level to the bottom place with the lowest influence level. Relatively, high influence level is considered for high weight as shown in the linear distribution as suggested by Darlis in 2016 [31]. By applying the weight allocating method by Robbins et al. in 2012, the haemodynamic parameter with the highest influence level is given any weight number as a reference. Then, the weight of the haemodynamic parameter below is given according to the specified influence level. The total weight value used in the present study is equals to one as shown in Table 7. Table 8 displays an example of scoring stage matrix based on equation (11) for all haemodynamic and statistical parameters. In the end, a final ranking of the analysed stent strut configurations could be obtained.

Table 7 - Weightage considered for each haemodynamic parameter.

\begin{tabular}{|c|c|c|}
\hline Haemodynamic Parameter & Influence level & Considered weight, $w$ \\
\hline TAWSS $_{\text {low }}$ & $\begin{array}{c}\text { Very high }[32,33,18,34,35,20,17,36-39 \\
15,40-43,28,16,44-55,19,29]\end{array}$ & 0.23 \\
\hline TAWSSG & $\begin{array}{c}\text { Slightly high }[35,17,36,38,39,15,43,52- \\
55,19,29,56-70]\end{array}$ & 0.17 \\
\hline TAWSS $_{\text {norm }} /$ TAWSS & Moderate $[32,18,15,16,44,46,54,71-81]$ & 0.12 \\
\hline TAWSS $_{\text {high }}$ & Moderate $[32,40,16,44,45,48,51,54]$ & 0.12 \\
\hline OSI & $\begin{array}{c}\text { Moderate }[32,34,15,40,41,43,28,49,50, \\
52,53,29,71-83]\end{array}$ & 0.12 \\
\hline RRT & Moderate $[15,41,28,52,71-74,76-93]$ & 0.12 \\
\hline $\mathrm{FSP}_{\text {low }} / \mathrm{FSP}$ & Low $[15,21,94]$ & 0.06 \\
\hline \multirow[t]{2}{*}{$\mathrm{FSP}_{\text {high }}$} & Low $[15,21,94]$ & 0.06 \\
\hline & Total weight & 1.00 \\
\hline
\end{tabular}

Table 8 - Scoring stage matrix.

\begin{tabular}{|c|c|c|c|c|c|c|c|c|}
\hline Stent & $\begin{array}{c}\text { Weightage } \\
\text { A }\end{array}$ & $\begin{array}{c}\text { Rating } \\
\text { A }\end{array}$ & $\begin{array}{c}\text { Weightage } \\
\text { B }\end{array}$ & $\begin{array}{c}\text { Rating } \\
\text { B }\end{array}$ & $\begin{array}{c}\text { Weightage } \\
\text { C }\end{array}$ & $\begin{array}{c}\text { Rating } \\
\text { C }\end{array}$ & $\begin{array}{l}\text { Total } \\
\text { Score }\end{array}$ & Rank \\
\hline Тур & $w_{\lambda}$ & $r_{\mathrm{A}, \lambda}$ & $w_{\mathrm{B}}$ & $r_{\mathrm{B}, \lambda}$ & $w_{\mathrm{C}}$ & $r_{\mathrm{C}, \lambda}$ & $S_{\lambda}$ & $\mathrm{R}_{\lambda}$ \\
\hline Type $\phi$ & $w_{\mathrm{A}}$ & $r_{\mathrm{A}, \phi}$ & $w_{\mathrm{B}}$ & $r_{\mathrm{B}, \phi}$ & $w_{\mathrm{C}}$ & $r_{\mathrm{C}, \phi}$ & $S_{\phi}$ & $\mathrm{R}_{\phi}$ \\
\hline
\end{tabular}




\section{Result and Discussion}

\subsection{Haemodynamic Effects Due to the Stent Geometries}

Figure 4 shows the distribution of TAWSS, TAWSSG, OSI, RRT and FSP for stent strut configuration of Type I at NBP condition by using ANSYS FLUENT. From the Figure 4 (a), TAWSS was seen low near the contacting edge of the stent geometry, blood flow domain and the arterial wall, which the phenomenon was in agreement with a study by Hsiao et al. in 2012 where low TAWSS distribution occurs near the stent strut [33]. Figure 4 (b) shows the performance of TAWSSG where the distribution over $5000 \mathrm{~Pa} / \mathrm{m}$ was found on the contacting surface of axial blood flow and the circumferential stent strut wall. The TAWSSG distribution in the study had a similar situation with a previous study LaDisa et al. where high WSSG occurs near the edge of stent strut model and became low when distancing from the edges [39]. At Figure 4 (c), the haemodynamic parameter of OSI was seen high in the region of entrapped blood flow near the stent strut connector and the vertex of stent strut geometry. By referring to a previous study on stent models by Martin et al. in 2009, the resulted OSI distribution in current study was valid where the luminal surface area exposed to OSI larger than 0.2 was found near the connector region [95].

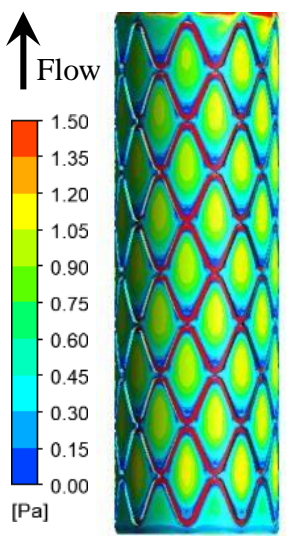

(a)

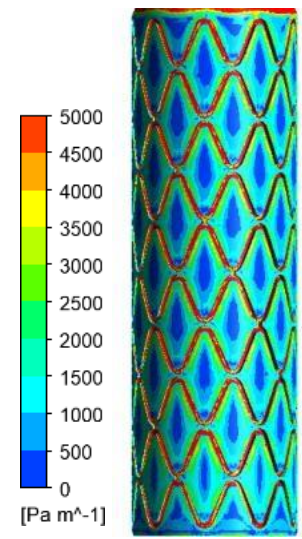

(b)

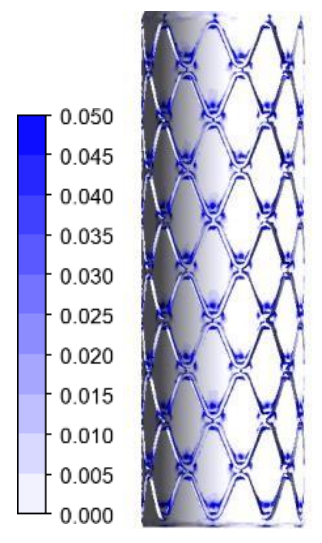

(c)

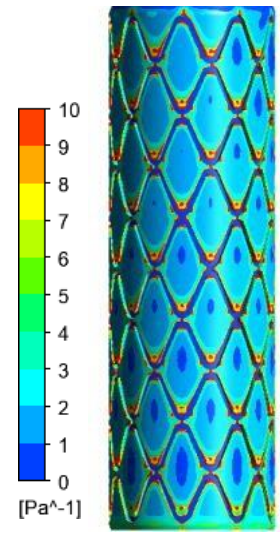

(d)

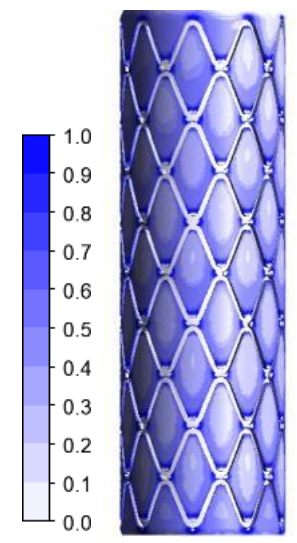

(e)

Fig. 4 - Distribution of (a) TAWSS, (b) TAWSSG, (c) OSI, (d) RRT and (e) FSP for stent strut configuration of Type I at NBP condition.

Table 9 - Haemodynamic and statistical performance of stent geometries for NBP condition.

\begin{tabular}{|c|c|c|c|c|c|c|}
\hline Parameter & Type I & Type II & Type III & Type IV & Type V & Type VI \\
\hline TAWSS low $(\%)$ & 12.849 & 12.725 & 14.030 & 14.869 & 11.795 & 11.141 \\
\hline TAWSS & 72.105 & 73.995 & 71.673 & 70.528 & 76.187 & 76.226 \\
\hline TAWSS $_{\text {high }}(\%)$ & 1.858 & 1.858 & 1.846 & 1.850 & 2.107 & 2.460 \\
\hline$\mu_{\text {TAWSS }}(\mathbf{P a})$ & 2.123 & 2.142 & 2.099 & 2.082 & 2.216 & 2.262 \\
\hline$K_{\text {TAWSS }}$ & 15.905 & 15.546 & 17.145 & 15.764 & 14.189 & 14.142 \\
\hline TAWSSG (\%) & 90.185 & 88.776 & 89.972 & 89.664 & 86.771 & 87.543 \\
\hline$\mu$ TAWSSG $(\mathbf{P a} / \mathbf{m})$ & 21157 & 2436 & 2251 & 9384 & 8386362 & 1799555 \\
\hline$K_{\text {TAWSSG }}$ & 348160 & 533134 & 631996 & 703855 & 18034 & 525588 \\
\hline OSI (\%) & 99.736 & 99.631 & 99.688 & 99.665 & 99.737 & 99.843 \\
\hline$\mu \mathrm{OSI}$ & 0.00535 & 0.00498 & 0.00473 & 0.00545 & 0.00438 & 0.00407 \\
\hline KosI & 86.606 & 123.770 & 129.287 & 102.926 & 130.354 & 131.777 \\
\hline RRT (\%) & 98.175 & 98.021 & 97.760 & 96.635 & 98.509 & 98.636 \\
\hline$\mu_{\mathrm{RRT}}\left(\mathbf{P a}^{-1}\right)$ & 1.380 & 1.566 & 1.639 & 1.798 & 1.747 & 1.394 \\
\hline$K_{\text {RRT }}$ & 244551 & 15938 & 56493 & 328700 & 575701 & 118272 \\
\hline $\operatorname{FSP}_{\text {low }}(\%)$ & 66.854 & 66.019 & 66.099 & 65.704 & 65.752 & 66.261 \\
\hline $\operatorname{FSP}_{\text {high }}(\%)$ & 18.375 & 18.265 & 19.286 & 20.844 & 15.530 & 17.011 \\
\hline$\mu_{\mathrm{FSP}}$ & 0.171 & 0.179 & 0.180 & 0.185 & 0.173 & 0.175 \\
\hline$K_{\text {FSP }}$ & 3.693 & 3.541 & 3.582 & 3.282 & 3.763 & 3.578 \\
\hline
\end{tabular}

Figure $4(\mathrm{~d})$ shows the luminal surface area of RRT distribution over $10 \mathrm{~Pa}^{-1}$ was also found at the connector region where the atherogenic particles were predicted to remain contact onto the particular region. This event was similar to a previous study by De Santis et al. in 2013 where the RRT distribution is peaked around the stent strut geometry especially the region of entrapped blood flow near the short connector [96]. Lastly, Figure 4 (e) shows a 
distribution of FSP that was seen high near the stent strut geometry but became low when distancing away from the stent strut geometry due to the separated blood flow from its mainstream as the blood hits the stent strut geometry. In 2005, He et al. also got the similar FSP phenomenon as in the present study where the FSP was high near the stent strut geometry [21]. Thus, the haemodynamic effects due to the stent strut geometries in the present simulation were valid.

Table 10 - Haemodynamic and statistical performance of stent geometries for $\mathrm{PH}$ condition.

\begin{tabular}{|c|c|c|c|c|c|c|}
\hline Parameter & Type I & Type II & Type III & Type IV & Type V & Type VI \\
\hline TAWSS $_{\text {low }}(\%)$ & 12.348 & 12.152 & 13.307 & 14.257 & 11.365 & 10.568 \\
\hline TAWSS & 73.120 & 74.710 & 72.637 & 71.475 & 76.400 & 76.382 \\
\hline TAWSShigh $(\%)$ & 2.169 & 2.190 & 2.148 & 2.127 & 2.429 & 2.896 \\
\hline$\mu$ TAWSS (Pa) & 2.233 & 2.258 & 2.213 & 2.195 & 2.327 & 2.380 \\
\hline$K_{\text {TAWSS }}$ & 15.846 & 15.503 & 16.939 & 15.832 & 14.226 & 14.125 \\
\hline TAWSSG $(\%)$ & 89.863 & 88.318 & 89.572 & 89.334 & 86.409 & 87.075 \\
\hline$\mu_{\text {TAWSSG }}(\mathrm{Pa} / \mathrm{m})$ & 21648 & 2540 & 2370 & 10080 & 9062953 & 1885242 \\
\hline$K_{\text {TAWSSG }}$ & 350468 & 452212 & 563322 & 700515 & 18044 & 525827 \\
\hline OSI (\%) & 99.738 & 99.632 & 99.685 & 99.665 & 99.727 & 99.847 \\
\hline$\mu_{\mathrm{OSI}}$ & 0.00531 & 0.00495 & 0.00471 & 0.00540 & 0.00433 & 0.00404 \\
\hline KOSI & 87.164 & 127.104 & 130.664 & 103.130 & 131.950 & 134.762 \\
\hline RRT (\%) & 98.338 & 98.200 & 97.982 & 96.804 & 98.581 & 98.703 \\
\hline$\mu_{\mathrm{RRT}}\left(\mathbf{P a}^{-1}\right)$ & 1.303 & 1.483 & 1.545 & 1.729 & 1.675 & 1.339 \\
\hline$K_{\mathrm{RRT}}$ & 5185 & 63529 & 131262 & 38516 & 199864 & 330443 \\
\hline $\operatorname{FSP}_{\text {low }}(\%)$ & 76.921 & 76.238 & 75.999 & 75.197 & 75.166 & 75.696 \\
\hline $\operatorname{FSP}_{\text {high }}(\%)$ & 16.648 & 16.762 & 17.497 & 19.196 & 12.739 & 14.249 \\
\hline$\mu_{\mathrm{FSP}}$ & 0.132 & 0.140 & 0.140 & 0.146 & 0.131 & 0.135 \\
\hline$K_{\text {FSP }}$ & 5.190 & 4.772 & 4.937 & 4.543 & 5.541 & 5.174 \\
\hline
\end{tabular}

Table 11 - Haemodynamic and statistical performance of stent geometries for HS1 condition.

\begin{tabular}{|c|c|c|c|c|c|c|}
\hline Parameter & Type I & Type II & Type III & Type IV & Type V & Type VI \\
\hline TAWSS $_{\text {low }}(\%)$ & 12.082 & 11.545 & 12.748 & 13.784 & 10.433 & 9.622 \\
\hline TAWSS & 73.752 & 75.670 & 73.364 & 72.281 & 77.036 & 76.712 \\
\hline TAWSS $_{\text {high }}(\%)$ & 2.796 & 2.830 & 2.777 & 2.765 & 3.249 & 3.863 \\
\hline$\mu_{\text {TAWSS }}(\mathbf{P a})$ & 2.402 & 2.442 & 2.386 & 2.365 & 2.532 & 2.597 \\
\hline$K_{\text {TAWSS }}$ & 15.172 & 14.835 & 16.002 & 15.049 & 13.799 & 13.604 \\
\hline TAWSSG (\%) & 89.343 & 87.412 & 88.882 & 88.816 & 84.786 & 85.671 \\
\hline$\mu_{\text {TAWSSG }}(\mathbf{P a} / \mathbf{m})$ & 24653 & 2777 & 2558 & 10557 & 9806979 & 1970949 \\
\hline$K_{\text {TAWSSG }}$ & 355782 & 115114 & 447292 & 672883 & 18051 & 525963 \\
\hline OSI (\%) & 99.738 & 99.629 & 99.674 & 99.654 & 99.736 & 99.856 \\
\hline MOSI & 0.00546 & 0.00508 & 0.00485 & 0.00558 & 0.00442 & 0.00405 \\
\hline KosI & 82.757 & 119.678 & 124.612 & 95.400 & 133.674 & 122.511 \\
\hline RRT (\%) & 98.379 & 98.331 & 98.080 & 97.019 & 98.699 & 98.868 \\
\hline$\mu_{\mathrm{RRT}}\left(\mathbf{P a}^{-1}\right)$ & 1.263 & 1.353 & 1.448 & 1.596 & 1.524 & 1.217 \\
\hline$K_{\text {RRT }}$ & 614 & 5778 & 164978 & 110342 & 302662 & 428245 \\
\hline $\operatorname{FSP}_{\text {low }}(\%)$ & 81.139 & 81.068 & 81.172 & 80.267 & 80.310 & 79.091 \\
\hline $\operatorname{FSP}_{\text {high }}(\%)$ & 11.552 & 11.386 & 11.897 & 13.952 & 9.366 & 9.963 \\
\hline$\mu_{\mathrm{FSP}}$ & 0.108 & 0.110 & 0.112 & 0.120 & 0.107 & 0.113 \\
\hline$K_{\text {FSP }}$ & 7.426 & 7.250 & 7.153 & 6.355 & 7.865 & 7.326 \\
\hline
\end{tabular}

According to the allowable haemodynamic threshold in section 2.3 and the statistical properties in section 2.4 , a set of performance data for each stent strut configuration at specific physiological condition is then extracted as shown in Table 9, Table 10 and Table 11 by using MATLAB. In Figure 4, the shape of the modelled blood flow of Type I can be identified for its performance of the allowable haemodynamic parameters on the luminal surface as shown in Table 9. Figure 4(a) gives the percentage area of luminal surface for TAWSS $73.120 \%$ and $2.233 \%$, respectively. Percentage area of the luminal surface exposed to TAWSSG less than $5000 \mathrm{~Pa} / \mathrm{m}$ in Figure 4 (b) gives $89.863 \%$. In Figure 4 (c), luminal surface area that exposed to OSI less than 0.2 produces $99.738 \%$. Figure 4 (d) shows the area of luminal surface exposed to RRT less than $10 \mathrm{~Pa}^{-1}$ about $98.338 \%$. For FSP, Figure 4 (e) shows luminal surface area exposed to $\mathrm{FSP}_{\text {low }}$ about $76.921 \%$ while $\mathrm{FSP}_{\text {high }}$ is at $16.648 \%$. The performance for luminal surface area exposed to allowable parameter threshold of other stents are varied according to the physiological flow conditions as shown in Table 9, Table 10 and Table 11. 
The statistical properties for computational model of Type I at NBP condition also are identified as in Table 9. For TAWSS, $\mu_{\text {TAws }}$ is shown to have $2.123 \mathrm{~Pa}$ while $K_{\text {TAws }}$ is about 15.905 . However, Type VI stent has the highest favourable $\mu_{\text {TAwsS }}$ of 2.262 Pa for NBP condition, 2.380 Pa for PH condition and 2.597 Pa for HS1 condition, as shown in Table 9, Table 10 and Table 11. For kurtosis, Type III stent has the highest desired performance of $K_{\text {TAwss }}$ of 17.145 for NBP condition, 16.939 for PH condition and 16.002 for HS1 condition. This is similar to a previous study by Murphy et al. 2010 where high kurtosis is desirable for good WSS distribution [22]. For statistical TAWSSG performance, Type I obtains quite high value of $\mu_{\mathrm{TAWSSG}}$ and $K_{\mathrm{TAwWSSG}}$ about $21157 \mathrm{~Pa} / \mathrm{m}$ and 348160, respectively. On the other hand, the desired low $\mu_{\text {TAwsSG }}$ achieved by Type III stent with $2251 \mathrm{~Pa} / \mathrm{m}$ for NBP condition, $2370 \mathrm{~Pa} / \mathrm{m}$ for $\mathrm{PH}$ condition and $2558 \mathrm{~Pa} / \mathrm{m}$ for HS1 condition. The desired high $K_{\text {TAwwss }}$ was achieved by Type IV stent with 703855 for NBP condition, 700515 for PH condition and 672883 for HS1 condition. In addition, the statistical TAWSSG performance Type IV stent is in agreement with the study by Murphy et al. that desires low mean and high kurtosis for WSSG distribution [22]. The least favourable statistical performance was seen in Type V stent due to its high mean and low kurtosis among other stents. In addition, the desirable low mean and high kurtosis is also applied to OSI, RRT and FSP in obtaining the best statistical properties as shown in Table 9, Table 10 and Table 11.

The obtained haemodynamic and statistical performances among the stents might not have large significant change. However, the data obtained is only for one cardiac cycle which equivalent to 0.8 second of the cardiovascular system. If the result was followed up for 30 days, the result could have large significant change. Therefore, the small significant change among the stent performance in the data of current study is very important. Thus, Stent Pictorial Selection Method plays a big role to determine the stent strut configuration.

\subsection{Evaluated Performance through Stent Pictorial Selection Method: Screening Stage}

The first part of Stent Pictorial Selection Method shows the screening process showed rough evaluation based on reference value of haemodynamic performance as seen in Table 3. This rough evaluation scored the discrepancy in each haemodynamic parameter that deviates from the reference performance. Tables 12, 13 and 14 showed the screened haemodynamic performances through the relative score assignation of each stent geometry in every studied physiological condition. Net score is the summation of '+' minus to the summation of '-'. Based on the net score, an initial ranking for each blood condition was obtained to indicate how close or far of the carotid artery implanted with stent strut haemodynamic performances to the unstented healthy carotid artery.

In NBP condition, Type I, Type II, Type III and Type IV have the net score of -6 which were better than Type V and Type VI that has the net score of -8 . Although there were a difference between the obtained net scores, the haemodynamic performances of the stented carotid artery was still far from the unstented healthy carotid artery. In the hypertensive condition of $\mathrm{PH}$ and HS1, all of the studied stent strut configurations have the worst similar net score of 8. This was due to the effect of hypertensive blood flow condition causing instable haemodynamic characteristics. Therefore, the net scores for hypertensive condition become worsen. However, the initial ranking from the net score was not a finalised evaluation because the resulting scores were still qualitative. To include the statistical performances with a detailed haemodynamic parameter scores, the current evaluation was continued to rating process.

Table 12 - Screening of stent performance in NBP condition.

Luminal surface area exposed to haemodynamic parameter

\begin{tabular}{ccccccccccc} 
Stent & $\begin{array}{c}\text { TAWSS } \\
\text { low }\end{array}$ & $\begin{array}{c}\text { TAWSS } \\
\text { norm }\end{array}$ & $\begin{array}{c}\text { TAWSS } \\
\text { high }\end{array}$ & TAWSSG & OSI & RRT & $\begin{array}{c}\text { FSP } \\
\text { high }\end{array}$ & $\begin{array}{c}\text { FSP } \\
\text { low }\end{array}$ & $\begin{array}{c}\text { Net } \\
\text { score }\end{array}$ \\
\hline Type I & - & - & + & - & - & - & - & - & -6 \\
Type II & - & - & + & - & - & - & - & - & -6 \\
Type III & - & - & + & - & - & - & - & - & -6 \\
Type IV & - & - & + & - & - & - & - & - & -6 \\
Type V & - & - & - & - & - & - & - & - & -8 \\
Type VI & - & - & - & - & - & - & - & - & -8 \\
\hline
\end{tabular}


Table 13 - Screening of stent performance in $\mathrm{PH}$ condition.

Luminal surface area exposed to haemodynamic parameter

\begin{tabular}{ccccccccccc} 
Stent & \begin{tabular}{c}
\cline { 2 - 5 } \\
\cline { 2 - 6 } \\
low
\end{tabular} & $\begin{array}{c}\text { TAWSS } \\
\text { norm }\end{array}$ & $\begin{array}{c}\text { TAWSS } \\
\text { high }\end{array}$ & TAWSSG & OSI & RRT & $\begin{array}{c}\text { FSP } \\
\text { high }\end{array}$ & $\begin{array}{c}\text { FSP } \\
\text { low }\end{array}$ & $\begin{array}{c}\text { Net } \\
\text { score }\end{array}$ \\
\hline Type I & - & - & - & - & - & - & - & - & -8 \\
Type II & - & - & - & - & - & - & - & - & -8 \\
Type III & - & - & - & - & - & - & - & - & -8 \\
Type IV & - & - & - & - & - & - & - & - & -8 \\
Type V & - & - & - & - & - & - & - & - & -8 \\
Type VI & - & - & - & - & - & - & - & - & -8 \\
\hline
\end{tabular}

Table 14 - Screening of stent performance in HS1 condition.

Luminal surface area exposed to haemodynamic parameter

\begin{tabular}{ccccccccccc} 
Stent & \begin{tabular}{c}
\cline { 2 - 5 } \\
\cline { 2 - 7 } \\
low
\end{tabular} & $\begin{array}{c}\text { TAWS } \\
\text { norm }\end{array}$ & $\begin{array}{c}\text { TAWSS } \\
\text { high }\end{array}$ & TAWSSG & OSI & RRT & $\begin{array}{c}\text { FSP } \\
\text { high }\end{array}$ & $\begin{array}{c}\text { FSP } \\
\text { low }\end{array}$ & $\begin{array}{c}\text { Net } \\
\text { score }\end{array}$ \\
\hline Type I & - & - & - & - & - & - & - & - & -8 \\
Type II & - & - & - & - & - & - & - & - & -8 \\
Type III & - & - & - & - & - & - & - & - & -8 \\
Type IV & - & - & - & - & - & - & - & - & -8 \\
Type V & - & - & - & - & - & - & - & - & -8 \\
Type VI & - & - & - & - & - & - & - & - & -8
\end{tabular}

\subsection{Evaluated Performance through Stent Pictorial Selection Method: Rating and Scoring Stage}

This part of Stent Pictorial Selection Method shows the process rates of the performance for the luminal surface area percentage exposed to haemodynamic parameters and the statistical properties as explained in further discussion. The rating $(R t)$ was ranged from the worst to the best as indicated using values from 1 to 6 . The scoring process depends on to the weightage of each haemodynamic performance. Net score from the screening process indicates how much the haemodynamic parameters changed by the stent geometries. From the obtained weightage, the scoring process was done for each haemodynamic parameter.

\section{Time Averaged Wall Shear Stress (TAWSS)}

In Table 15, Type V and Type VI stents have excellent TAWSS mean rating compared to other stent geometries for all physiological conditions. The highest rating of kurtosis TAWSS in NBP condition was Type I stent, but the PH and HS1 condition showed Type III stent. Type VI stent has the highest rating of TAWSS low $_{\text {for the least luminal }}$ surface area percentage in all physiological conditions. This proved that the geometry of Type VI stent was better than other stents in controlling the atherosclerosis activity. Type IV stent has the lowest rating for TAWSS norm $_{\text {among the }}$ studied stent geometries in all physiological conditions. Therefore, Type IV stent was considered as the least preferred

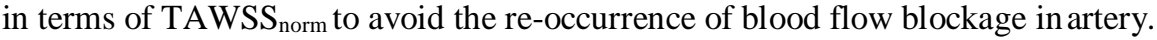

For all physiological conditions, Table 15 showed Type VI stent with the least TAWSS ${ }_{\text {high }}$ rating, indicating that the stent geometry is less capable in controlling the thrombosis formation compared to other stent geometries. In NBP

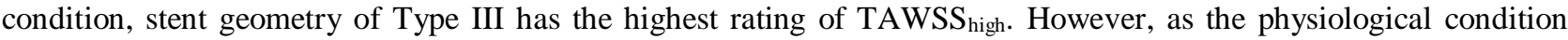

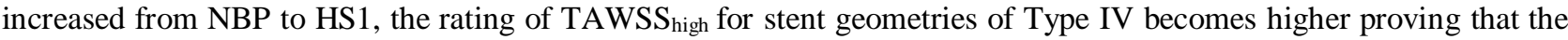
capabilities to overcome high shear thrombosis formation have become stronger.

Table 15 shows the scoring process of TAWSS performance for all physiological conditions. Stent geometry of Type VI appeared to have the highest TAWSS score of 3.06 for normotensive condition while Type V stent showed the highest score of 2.95 for hypertensive condition. However, Type IV stent presented the lowest TAWSS score in NBP, PH and HS1 conditions at 1.55, 1.67 and 1.67, respectively. Meanwhile, the stent geometry of Type I, Type II and Type IIII stents showed moderate TAWSS performance in avoiding atherosclerosis and high shear thrombosis. Therefore, 
Type V and Type VI stents were considered very suitable to be implanted in carotid artery for normotensive and hypertensive blood condition to obtain outstanding distribution performance of TAWSS.

Table 15 - Rating and scoring stage for TAWSS distribution.

\begin{tabular}{|c|c|c|c|c|c|c|c|c|c|c|c|c|c|}
\hline \multirow{21}{*}{ 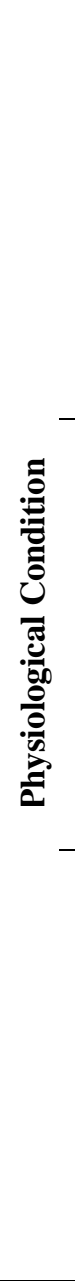 } & \multirow{7}{*}{ 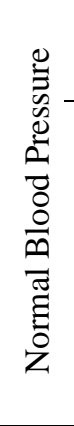 } & Stent & $\begin{array}{c}\text { TAWSS }_{\text {low }} \\
(\%)\end{array}$ & $R t$ & $\begin{array}{c}\text { TAWSS }_{\text {norm }} \\
(\%)\end{array}$ & $R t$ & $\begin{array}{c}\text { TAWSS }_{\text {high }} \\
(\%)\end{array}$ & $R t$ & $\mu$ & $R t$ & $K$ & $R t$ & Score \\
\hline & & Type I & 12.85 & 3 & 72.10 & 3 & 1.86 & 4 & 2.12 & 3 & 15.91 & 5 & 2.49 \\
\hline & & Type II & 12.73 & 4 & 73.99 & 4 & 1.86 & 3 & 2.14 & 4 & 15.55 & 3 & 2.60 \\
\hline & & Type III & 14.03 & 2 & 71.67 & 2 & 1.85 & 6 & 2.10 & 2 & 17.15 & 6 & 2.38 \\
\hline & & Type IV & 14.87 & 1 & 70.53 & 1 & 1.85 & 5 & 2.08 & 1 & 15.76 & 4 & 1.55 \\
\hline & & Type V & 11.79 & 5 & 76.19 & 5 & 2.11 & 2 & 2.22 & 5 & 14.19 & 2 & 2.83 \\
\hline & & Type VI & 11.14 & 6 & 76.23 & 6 & 2.46 & 1 & 2.26 & 6 & 14.14 & 1 & 3.06 \\
\hline & \multirow{7}{*}{ 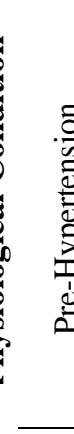 } & Stent & $\begin{array}{c}\text { TAWSS }_{\text {low }} \\
(\%)\end{array}$ & $R t$ & $\begin{array}{c}\text { TAWSS }_{\text {norm }} \\
(\%)\end{array}$ & $R t$ & $\begin{array}{c}\text { TAWSS }_{\text {high }} \\
(\%)\end{array}$ & $R t$ & $\mu$ & $R t$ & $K$ & $R t$ & Score \\
\hline & & Type I & 12.35 & 3 & 73.12 & 3 & 2.17 & 4 & 2.23 & 3 & 15.85 & 5 & 2.49 \\
\hline & & Type II & 12.15 & 4 & 74.71 & 4 & 2.19 & 3 & 2.26 & 4 & 15.50 & 3 & 2.60 \\
\hline & & Type III & 13.31 & 2 & 72.64 & 2 & 2.15 & 5 & 2.21 & 2 & 16.94 & 6 & 2.26 \\
\hline & & Type IV & 14.26 & 1 & 71.48 & 1 & 2.13 & 6 & 2.19 & 1 & 15.83 & 4 & 1.67 \\
\hline & & Type V & 11.36 & 5 & 76.40 & 6 & 2.43 & 2 & 2.33 & 5 & 14.23 & 2 & 2.95 \\
\hline & & Type VI & 10.57 & 6 & 76.38 & 5 & 2.90 & 1 & 2.38 & 6 & 14.13 & 1 & 2.94 \\
\hline & \multirow{7}{*}{ 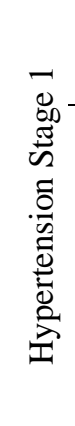 } & Stent & $\begin{array}{c}\text { TAWSS }_{\text {low }} \\
(\%)\end{array}$ & $R t$ & $\begin{array}{c}\text { TAWSS }_{\text {norm }} \\
(\%)\end{array}$ & $R t$ & $\begin{array}{c}\text { TAWSS } \text { Thigh }^{(\%)} \\
\text {. }\end{array}$ & $R t$ & $\mu$ & $R t$ & $K$ & $R t$ & Score \\
\hline & & Type I & 12.08 & 3 & 73.75 & 3 & 2.80 & 4 & 2.40 & 3 & 15.17 & 5 & 2.49 \\
\hline & & Type II & 11.55 & 4 & 75.67 & 4 & 2.83 & 3 & 2.44 & 4 & 14.84 & 3 & 2.60 \\
\hline & & Type III & 12.75 & 2 & 73.36 & 2 & 2.78 & 5 & 2.39 & 2 & 16.00 & 6 & 2.26 \\
\hline & & Type IV & 13.78 & 1 & 72.28 & 1 & 2.76 & 6 & 2.37 & 1 & 15.05 & 4 & 1.67 \\
\hline & & Type V & 10.43 & 5 & 77.04 & 6 & 3.25 & 2 & 2.53 & 5 & 13.80 & 2 & 2.95 \\
\hline & & Type VI & 9.62 & 6 & 76.71 & 5 & 3.86 & 1 & 2.60 & 6 & 13.60 & 1 & 2.94 \\
\hline
\end{tabular}

${ }^{*} w_{\text {TAWSSlow }}=0.23, w_{\text {TAWSSnorm }}=0.12, w_{\text {TAWSShigh }}=0.12, w_{\mu}=0.12$ and $w_{\mathrm{K}}=0.12$

\section{Time Averaged Wall Shear Stress Gradient (TAWSSG)}

Table 16 illustrates the rating as well as scoring of mean, kurtosis and luminal surface area percentage exposed to TAWSSG that are equal to or less than $5000 \mathrm{~Pa} / \mathrm{m}$. Type III stent has the highest rating of mean compared to other stent geometries for all blood conditions. In NBP condition, stent geometry of Type II, Type III and Type IV have the most excellent rating of kurtosis. Meanwhile in PH and HS1 conditions, stent geometries of Type III and Type IV have good kurtosis rating. In overall conditions, only Type IV stent has the most optimum kurtosis performance with the highest rating. Regarding percentage area of lumen exposed to the desired TAWSSG in all physiological conditions, stent geometries of Type I, Type III and Type IV have high rating for the haemodynamic parameter. By focusing on Type I, the stent has the highest rating for the capability of obtaining the most luminal surface area exposed to the desired TAWSSG in reducing the formation of proliferated endothelial cell layer.

Table 16 illustrated that Type III stent has the highest score for TAWSSG performance in all blood conditions. However, the TAWSSG performance of Type III stent was seen slightly reduced from the score of 2.72 in NBP condition to the score of 2.55 in HS1 condition. Type V stent has the least performance of TAWSSG in all physiological conditions with the score of 0.51 proving its geometry was not suitable for the reduction of high TAWSSG distribution. As the blood condition increases from NBP to HS1, the TAWSSG performance of Type II stent decreased from 2.04 score to 1.70 score. Thus, Type II stent was not suitable for a high blood flow physiological condition. On the other hand, Type I stent was shown to have moderate performance in all physiological conditions where the score was neither the highest nor the lowest. 
Table 16 - Rating and scoring stage for TAWSSG distribution.

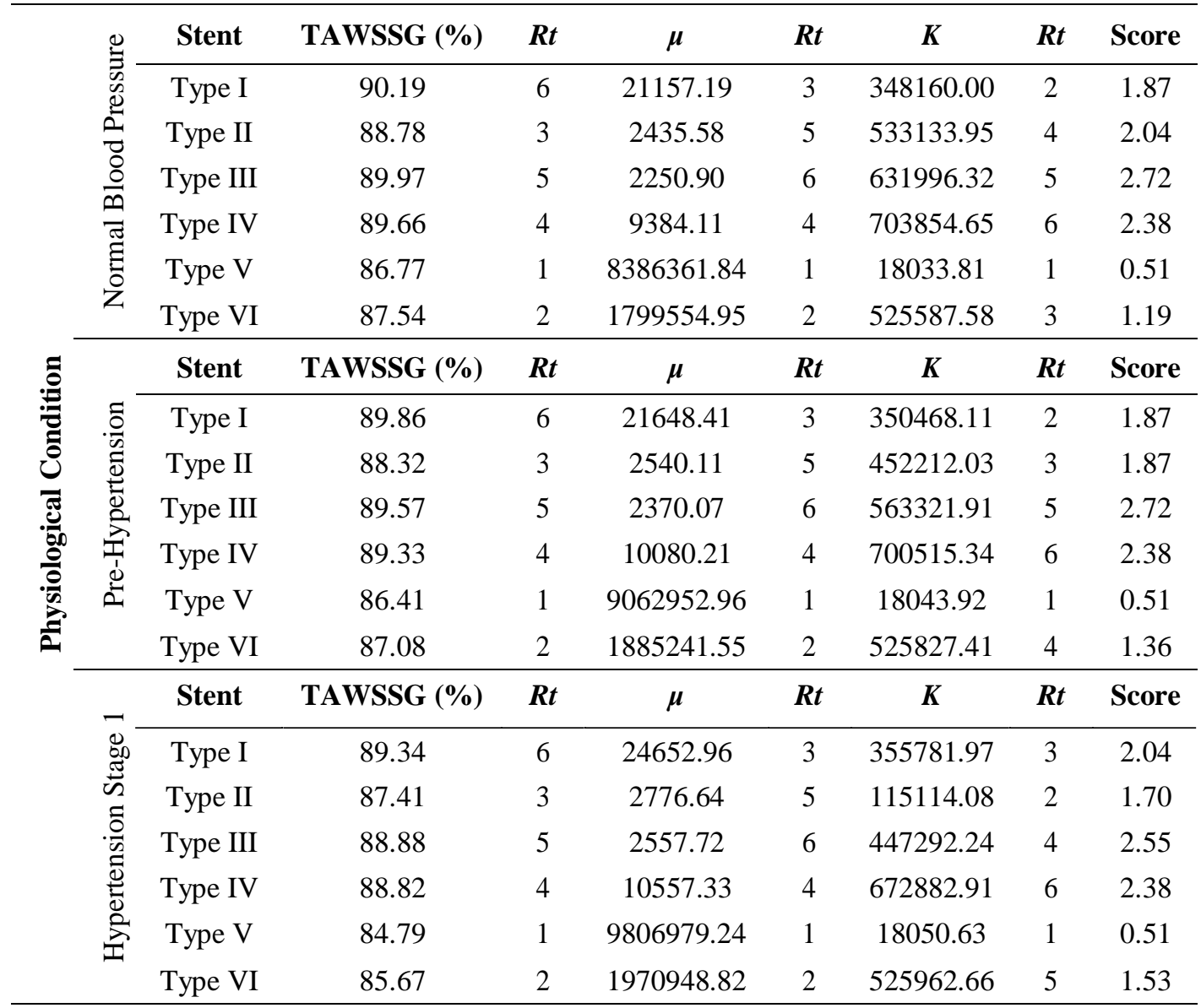

$* w_{\mathrm{TAWSSG}}=0.17, w_{\mu}=0.17$ and $w_{\mathrm{K}}=0.17$

\section{Oscillatory Shear Index (OSI)}

The statistical performance and the percentage of luminal surface area exposed to OSI equal to and less than 0.2 were rated and scored as shown in Table 17. For all physiological conditions, Type VI stent has the highest rating for the least mean value than other stent geometries. The highest rating of kurtosis as indicated by NBP and PH conditions was achieved by Type VI stent while HS1 condition displayed Type V stent. However, Type I and Type IV stents have the lowest rating of statistical properties due to poor capability in achieving the desired values.

In overall physiological condition, Type VI stents has the highest rating for the most excellent performance in getting the considerable amount of luminal surface area exposed to OSI equal to and less than 0.2. However, the stent geometry of Type II has the lowest rating for poor performance in obtaining the desired OSI distribution. The stent geometry with the most effective performance of OSI distribution could reduce the probability for atherosclerosis activity. It is apparent from Table 17 that Type VI stent has the highest score of OSI performance in all studied physiological conditions.

Therefore, Type VI stent has the highest score of OSI performance in all studied physiological conditions with an average score of 2.08. However, the OSI performance of this stent geometry type had slightly decreased from 2.16 score in NBP and PH conditions to 1.92 score in HS1 condition. Type V stent also showed high OSI performance as Type VI stent in HS1 condition with the score of 1.80. On the other hand, Type IV stent has a very low performance of OSI distribution with the score of only 0.60 in all physiological condition due to its geometrical shape that was not very suitable in controlling the oscillated vectors of wall shear stress. 
Table 17 - Rating and scoring stage for OSI distribution.

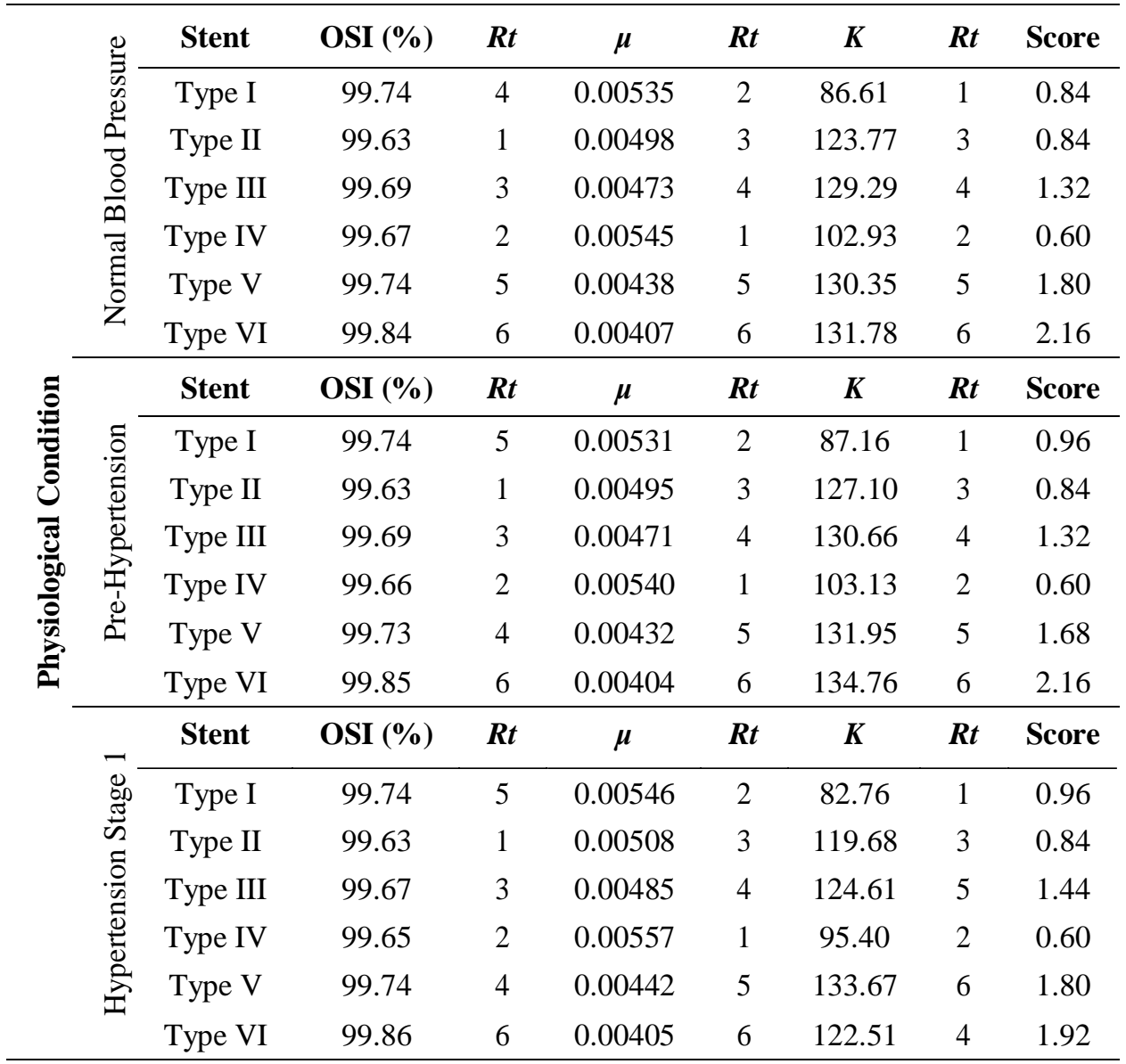

$* w_{\mathrm{OSI}}=0.12, w_{\mu}=0.12$ and $w_{\mathrm{K}}=0.12$

\section{Relative Residence Time (RRT)}

Table 18 displays the highest rating of mean RRT performance in NBP condition which achieved by Type I stent while the highest rating of kurtosis was obtained by Type V stent. In PH condition, the highest rating of mean goes to Type I but the highest rating of kurtosis goes to Type VI stent. Meanwhile in HS1 condition, the lowest rating of mean was acquired by Type IV stent, whereas the lowest rating of kurtosis was acquired by Type I stent. In addition to this physiological condition, Type VI excels with the highest rating for both mean and kurtosis performance. The highest rating of luminal surface area percentage exposed to the desired RRT was obtained by Type V and Type VI stents in all physiological conditions. Therefore, stent geometries of Type I and Type IV stents were less preferred in terms of RRT due to the low performance rating. This was due to the low RRT performances indicating that these stent geometries are less capable in reducing the stagnant atherogenic particles onto the arterial luminal surface.

Table 18 also shows different scores of RRT performance for normotensive and hypertensive blood conditions. High performance score of RRT distribution proved that the stent geometry was efficient to prevent localised atherogenic particles near the stent strut. In NBP condition, RRT performance by Type I and Type VI stents have the highest score of 1.68 while Type III and Type IV stents have the lowest score of 0.84 . In PH and HS1 condition, the best RRT performance was achieved by Type VI stent with an average score of 2.10, whereas the poorest RRT performance was obtained by Type IV stent with the score 0f 0.30. Meanwhile, the RRT score by Type II and Type V stents showed moderate RRT performance for all studied physiological conditions. 
Table 18 - Rating and scoring stage for RRT distribution.

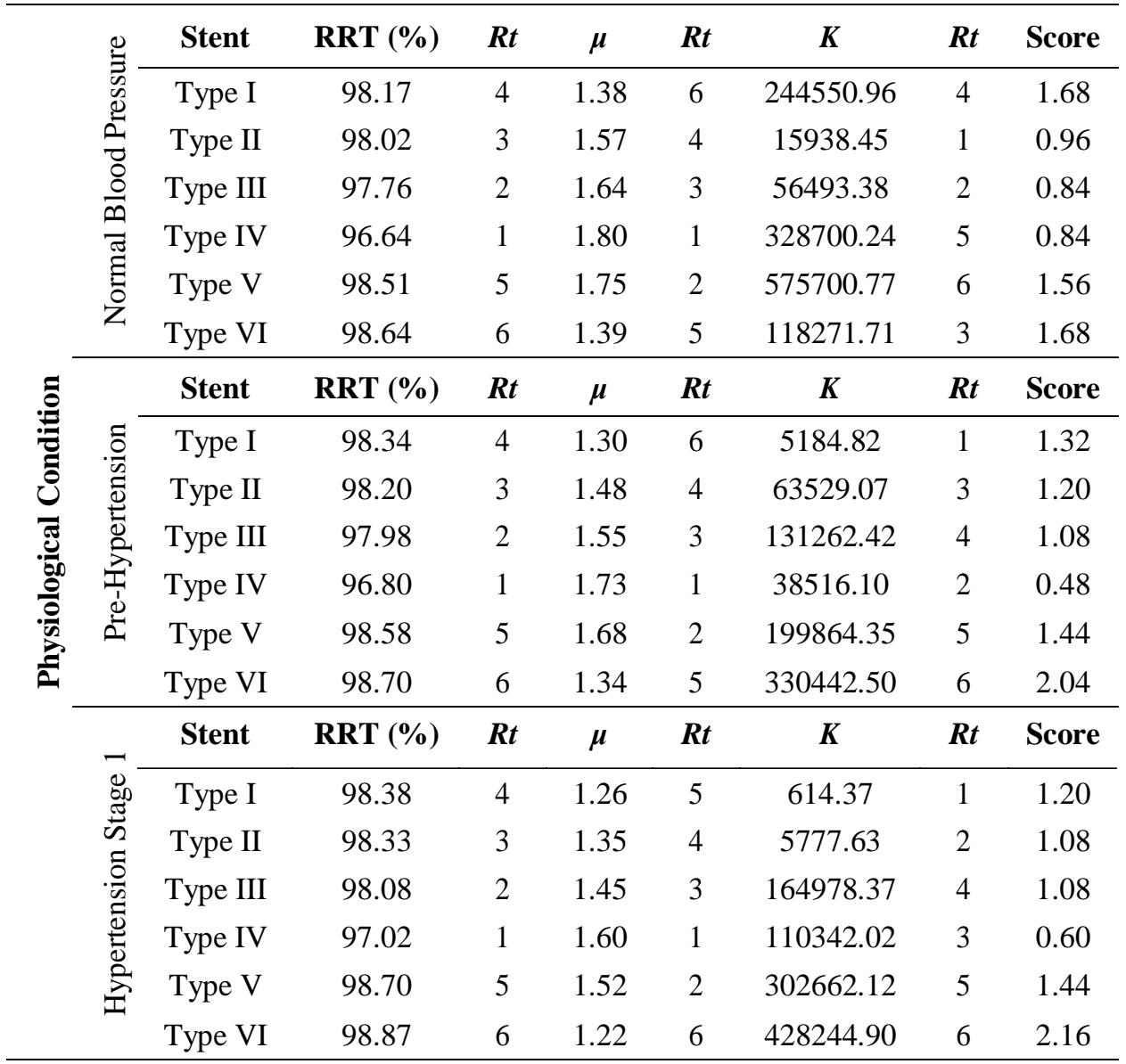

$* w_{\mathrm{RRT}}=0.12, w_{\mu}=0.12$ and $w_{\mathrm{K}}=0.12$

\section{Flow Separation Parameter (FSP)}

As shown in Table 19, mean FSP performances of Type I, Type II and Type V stents in HS1 condition have high rating among all study cases, whereas Type III and Type IV stents in NBP condition have low mean rating. For kurtosis, stent geometry of Type V stent in HS1 condition has the most desirable rating, whereas Type IV stent in NBP condition has the least rating. Table 19 points out that Type I and Type VI stents in NBP condition has a high rating for the percentage of luminal surface area exposed to $\mathrm{FSP}_{\text {low }}$ as compared to other stent geometries. For PH condition, the studied stent geometries of Type I and II have high rating due to the achieved high percentage of luminal surface area that exposed to $\mathrm{FSP}_{\text {low. }}$ Meanwhile in HS1 condition, the geometries of Type I and Type III stents have excellent rating with the capability to obtain high percentage of $\mathrm{FSP}_{\text {low }}$ compared to other stents. In overall, Type I stent was rated with

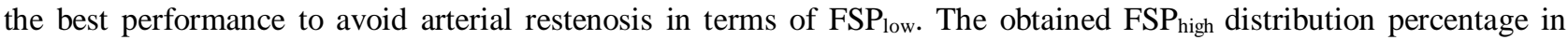
Table 19 decreased as the blood condition increases from NBP to HS1. Stent geometry of Type IV showed the lowest rating of $\mathrm{FSP}_{\text {high }}$ due its high percentage of luminal surface area. In overall, Type V stent geometry was seen capable in controlling $\mathrm{FSP}_{\text {high }}$ to prevent the proliferation of neo-intimal hyperplasia.

Thus, Type I stent appeared to have the highest score of FSP performance in NBP and PH physiological conditions with the score of 1.20. However in HS1 physiological condition, the geometry of Type V stent performed better FSP distribution than Type I stent with the score of 1.26. In overall physiological condition, geometry of Type IV showed the lowest FSP performance with an average score of only 0.28. Concurrently, the geometries of Type I, Type II, Type III and Type VI stents have moderate performance of FSP distribution. 
Table 19 - Rating and scoring stage for FSP distribution.

\begin{tabular}{|c|c|c|c|c|c|c|c|c|c|c|c|}
\hline \multirow{7}{*}{ 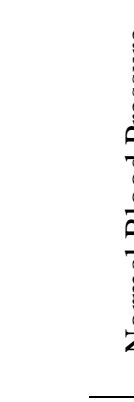 } & & Stent & $\operatorname{FSP}_{\text {high }}(\%)$ & $R t$ & $\operatorname{FSP}_{\text {low }}(\%)$ & $R t$ & $\mu$ & $R t$ & K & $R t$ & Score \\
\hline & & Type I & 18.38 & 6 & 66.85 & 3 & 0.17133 & 6 & 3.69 & 5 & 1.20 \\
\hline & & Type II & 18.27 & 3 & 66.02 & 4 & 0.17858 & 3 & 3.54 & 2 & 0.72 \\
\hline & & Type III & 19.29 & 4 & 66.10 & 2 & 0.17982 & 2 & 3.58 & 4 & 0.72 \\
\hline & & Type IV & 20.84 & 1 & 65.70 & 1 & 0.18453 & 1 & 3.28 & 1 & 0.24 \\
\hline & & Type V & 15.53 & 2 & 65.75 & 6 & 0.17281 & 5 & 3.76 & 6 & 1.14 \\
\hline & & Type VI & 17.01 & 5 & 66.26 & 5 & 0.17544 & 4 & 3.58 & 3 & 1.02 \\
\hline \multirow{14}{*}{ 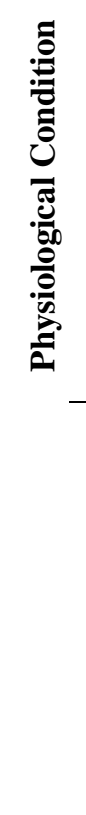 } & \multirow{7}{*}{ 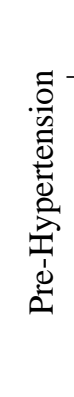 } & Stent & $\mathrm{FSP}_{\text {high }}(\%)$ & $R t$ & $\operatorname{FSP}_{\text {low }}(\%)$ & $R t$ & $\mu$ & $R t$ & K & $R t$ & Score \\
\hline & & Type I & 16.65 & 6 & 76.92 & 4 & 0.13180 & 5 & 5.19 & 5 & 1.20 \\
\hline & & Type II & 16.76 & 5 & 76.24 & 3 & 0.13955 & 3 & 4.77 & 2 & 0.78 \\
\hline & & Type III & 17.50 & 4 & 76.00 & 2 & 0.14010 & 2 & 4.94 & 3 & 0.66 \\
\hline & & Type IV & 19.20 & 2 & 75.20 & 1 & 0.14581 & 1 & 4.54 & 1 & 0.30 \\
\hline & & Type V & 12.74 & 1 & 75.17 & 6 & 0.13124 & 6 & 5.54 & 6 & 1.14 \\
\hline & & Type VI & 14.25 & 3 & 75.70 & 5 & 0.13479 & 4 & 5.17 & 4 & 0.96 \\
\hline & \multirow{7}{*}{ 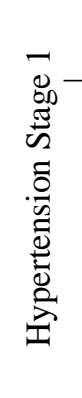 } & Stent & $\mathrm{FSP}_{\text {high }}(\%)$ & $R t$ & $\operatorname{FSP}_{\text {low }}(\%)$ & $R t$ & $\mu$ & $R t$ & K & $R t$ & Score \\
\hline & & Type I & 11.55 & 5 & 81.14 & 3 & 0.10784 & 5 & 7.43 & 5 & 1.08 \\
\hline & & Type II & 11.39 & 4 & 81.07 & 4 & 0.11005 & 4 & 7.25 & 3 & 0.90 \\
\hline & & Type III & 11.90 & 6 & 81.17 & 2 & 0.11210 & 3 & 7.15 & 2 & 0.78 \\
\hline & & Type IV & 13.95 & 2 & 80.27 & 1 & 0.11976 & 1 & 6.36 & 1 & 0.30 \\
\hline & & Type V & 9.37 & 3 & 80.31 & 6 & 0.10665 & 6 & 7.87 & 6 & 1.26 \\
\hline & & Type VI & 9.96 & 1 & 79.09 & 5 & 0.11334 & 2 & 7.33 & 4 & 0.72 \\
\hline
\end{tabular}

$* w_{\text {FSPlow }}=0.06, w_{\mathrm{FSPhigh}}=0.06, w_{\mu}=0.06$ and $w_{\mathrm{K}}=0.06$

\section{Rank of Stent for Specific Physiological Condition}

After the score of each haemodynamic parameter was determined, a total score was computed for overall stent performance according to each physiological condition. Table 20 displays the ranking of stent performance based on the total score. For all physiological conditions, the geometry of Type VI stent was proven to have the best overall performance of haemodynamic parameter with an average total score of 9.28. This stent geometry has a good overall performance based on the total score as the physiological condition increases from NBP to HS1. However, Type II and Type IV stents have low haemodynamic performance as the stents were ranked fifth and sixth, respectively. Type II has an average total score of 7.19 but Type IV stent showed the lowest average total score of only 5.53 compared to other stents as the physiological condition was increased from NBP to HS1. Therefore, Type IV stent became the least preferred for stent implantation to avoid arterial restenosis.

On the other hand, geometry of Type I, Type III and Type V stents have varying ranking for every physiological condition. Type V stent obtained the fourth rank in NBP condition with a total score of 7.84 and PH condition with the total score of 7.72. However, the rank of Type V stent increased to third place in HS1 condition. Type III stent that has the third rank in NBP condition with a total score 7.98 was increased to the second place with an average total score of 8.08 in PH and HS1 conditions. This was due to the performance of Type I and Type V that slightly dropped to third place in hypertensive condition. Type I stent was shown to have moderate haemodynamic performance among the studied stent geometries with an average score of 7.90. Although the stent performance was moderate, the performance became even worsen as the physiological condition increased from NBP to HS1. In NBP condition, Type I stent was ranked second with a total score of 8.08, but dropped to third in PH condition with the total score of 7.84. In HS1 condition, the rank of Type I stent for once again dropped to rank fourth with the total score of 7.77. This was due to the overall haemodynamic performance of Type I stent that incompetent to the total score of Type III, Type V and Type VI stents. 
Table 20 - Ranking of stent performance.

\begin{tabular}{|c|c|c|c|c|c|c|c|c|c|}
\hline \multirow{7}{*}{\multicolumn{2}{|c|}{ 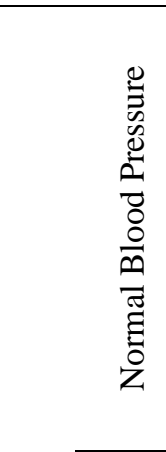 }} & Stent & TAWSS & TAWSSG & OSI & RRT & FSP & $\begin{array}{l}\text { Total } \\
\text { score }\end{array}$ & Rank \\
\hline & & Type I & 2.49 & 1.87 & 0.84 & 1.68 & 1.20 & 8.08 & 2 \\
\hline & & Type II & 2.60 & 2.04 & 0.84 & 0.96 & 0.72 & 7.16 & 5 \\
\hline & & Type III & 2.38 & 2.72 & 1.32 & 0.84 & 0.72 & 7.98 & 3 \\
\hline & & Type IV & 1.55 & 2.38 & 0.60 & 0.84 & 0.24 & 5.61 & 6 \\
\hline & & Type V & 2.83 & 0.51 & 1.80 & 1.56 & 1.14 & 7.84 & 4 \\
\hline & & Type VI & 3.06 & 1.19 & 2.16 & 1.68 & 1.02 & 9.11 & 1 \\
\hline \multirow{14}{*}{ 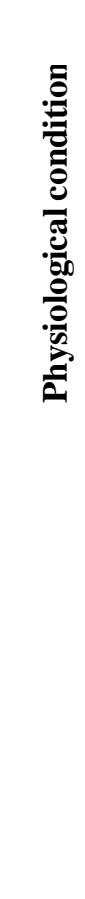 } & \multirow{7}{*}{ 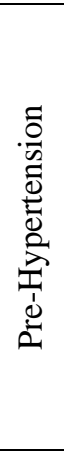 } & Stent & TAWSS & TAWSSG & OSI & RRT & FSP & $\begin{array}{l}\text { Total } \\
\text { score }\end{array}$ & Rank \\
\hline & & Type I & 2.49 & 1.87 & 0.96 & 1.32 & 1.20 & 7.84 & 3 \\
\hline & & Type II & 2.60 & 1.87 & 0.84 & 1.20 & 0.78 & 7.29 & 5 \\
\hline & & Type III & 2.26 & 2.72 & 1.32 & 1.08 & 0.66 & 8.04 & 2 \\
\hline & & Type IV & 1.67 & 2.38 & 0.60 & 0.48 & 0.30 & 5.43 & 6 \\
\hline & & Type V & 2.95 & 0.51 & 1.68 & 1.44 & 1.14 & 7.72 & 4 \\
\hline & & Type VI & 2.94 & 1.36 & 2.16 & 2.04 & 0.96 & 9.46 & 1 \\
\hline & \multirow{7}{*}{ 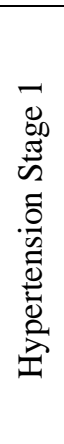 } & Stent & TAWSS & TAWSSG & OSI & RRT & FSP & $\begin{array}{l}\text { Total } \\
\text { score }\end{array}$ & Rank \\
\hline & & Type I & 2.49 & 2.04 & 0.96 & 1.20 & 1.08 & 7.77 & 4 \\
\hline & & Type II & 2.60 & 1.70 & 0.84 & 1.08 & 0.90 & 7.12 & 5 \\
\hline & & Type III & 2.26 & 2.55 & 1.44 & 1.08 & 0.78 & 8.11 & 2 \\
\hline & & Type IV & 1.67 & 2.38 & 0.60 & 0.60 & 0.30 & 5.55 & 6 \\
\hline & & Type V & 2.95 & 0.51 & 1.80 & 1.44 & 1.26 & 7.96 & 3 \\
\hline & & Type VI & 2.94 & 1.53 & 1.92 & 2.16 & 0.72 & 9.27 & 1 \\
\hline
\end{tabular}

At this point, the post-procedural event rates for each carotid stent in Table 1 reported by Bosiers et al. [1] can be clarified in terms of numerical CFD method and statistical evaluation system. From the present study, Type II stent was ranked fifth out of six studied stent in all physiological conditions. Since Type II stent resembled Precise device, it can be explained of why the device contributed about $0.7 \%$ of death after the stent implantation while other reported devices such as Protégé, Acculink and Exponent have 0.0\% of death event rate. This was due to very bad haemodynamic recirculation near the stent strut region that gave bad stent performance. Another clarification that can be made was minor stroke event rate which showing Acculink and Precise devices has the lowest minor stroke event rates about $0.7 \%$ as compared to other devices. By relating to current study, Type VI stent that resembled Acculink device was ranked first in all physiological conditions due to the most excellent haemodynamic performance as compared to other studied stent geometries. Thus, Type VI stent that resembled Acculink device has good performance in preventing haemodynamic recirculation that induced restenosis that lead to minor stroke. For major stroke, Exponent and Protégé devices have lesser event rates than Precise device with a difference of the event rates about $0.3 \%$. By relating to the present study, Type I and Type III stents that resembled Exponent and Protégé devices respectively, have better haemodynamic performance than Type II stent that resembled Precise device. This can be seen in Table 5.24 where Type I and Type III stents have better ranks than Type II stent.

\section{Conclusion and Future Recommendation}

The results from Stent Pictorial Selection Method depicted that Type VI stent has the best haemodynamic performance, whereas Type IV stent showed the worst haemodynamic performance for all cases in physiological conditions. The Type VI stent was shown superior in terms of stent performance for normotensive and hypertensive blood conditions with a total score of 9.28. However, Type IV stent was seen with the worst rank for the stent performance by the average total score of 5.53. On the other hand, the stent geometries of Type I, Type II, Type III and Type $\mathrm{V}$ have varying ranking of stent performance across all physiological conditions. The rank order from the best to worst in NBP condition was obtained by Type VI, Type I, Type III, Type V, Type II and Type IV, accordingly. For PH 
condition, the rank order was displayed as Type VI, Type III, Type I, Type V, Type II and Type IV. Meanwhile for the physiological condition of HS1, the rank order was illustrated as Type VI, Type III, Type V, Type I, Type II and Type IV. These rank orders were based on accumulated total scores from all of the studied haemodynamic parameters. In addition, different geometries of stent strut configuration in varying physiological condition gives different haemodynamic performances. Therefore, each stent strut configuration is not necessarily suitable for all normotensive and hypertensive physiological condition.

The limitation of the present study was only focused on haemodynamic recirculation which did not include stent structural analysis to fully elucidate of the restenosis formation. From the reported Table 1, Precise device had the least minor stroke event rates about $0.7 \%$ as same as Acculink device which the data were in contrary to the present study showing Type II stent that resembled Precise device performed worse than Type VI stent that resembled Acculink device.

Thus, a few recommendations that can be made by applying the method current study. Firstly, the method of CFD in the current study can be combined with finite element analysis (FEA) to form fluid-structure interaction (FSI) analysis, which can simulate the real complete situation of the blood flow of carotid artery in specific blood flow condition. In the end, the rank of Type II could change if Finite Element Analysis (FEA) was coupled with CFD method. Secondly, the study of artery that diseased with hypertension can be done in other types of artery such as femoral artery, brachial artery, renal artery and iliac artery. Lastly, the Stent Pictorial Selection Method is not only applicable for stent evaluation as it can be used to any medical devices implanted in human nervous system such as graft and cannula.

\section{Acknowledgement}

This work was funded by Kementerian Pendidikan Malaysia under Fundamental Research Grant Scheme (FRGS) Vot 1592.

\section{References}

[1] Bosiers, M., De Donato, G., Deloose, K., Verbist, J., Peeters, P., Castriota, F., Cremonesi, A. and Setacci, C. Does Free Cell Area Influence the Outcome in Carotid Artery Stenting?. Eur. J. Vasc. Endovasc. Surg., 2007, 33(2): 135-141.

[2] Bonati, L. H., Gregson, J., Dobson, J., McCabe, D. J. H., Nederkoorn, P. J., van der Worp, H. B., de Borst, G. J., Richards, T., Cleveland, T., Müller, M. D., Wolff, T., Engelter, S. T., Lyrer, P. A. and Brown, M. M. Restenosis and risk of stroke after stenting or endarterectomy for symptomatic carotid stenosis in the International Carotid Stenting Study (ICSS): secondary analysis of a randomised trial. Lancet Neurol, 2018, 17: 587-596.

[3] Kastrati, A., Mehilli, J., Dirschinger, J., Seyfarth, M. and Schmitt, C. Restenosis After Coronary Placement of Various Stent Types. Am. J. Cardiol., 2001, 87(1): 34-39.

[4] Schillinger, M., Gschwendtner, M., Reimers, B., Tremkler, J., Stockx, L., Mair, J., Macdonald, S., Karnel, F., Huber, K. and Minar, E. Does Carotid Stent Cell Design Matter?. Stroke, 2008, 39(3): 905-909.

[5] De Donato, G., Setacci, C., Deloose, K., Peeters, P., Cremonesi, A. and Bosiers, M. Long-Term Results of Carotid Artery Stenting. J. Vasc. Surg., 2008, 48(6): 1431-1441.

[6] Albertini, J.-N., Muller, L., Fouilhé, L. and Clément, C. Techniques Endoluminales de Traitement Des Lesions de la Bifurcation Carotidienne. EMC - Chir., 2005, 2(6): 659-685.

[7] Wissgott, C., Schmidt, W., Behrens, P., Brandt, C., Schmitz, K. P. and Andresen, R. Experimental Investigation of Modern and Established Carotid Stents. RoFo Fortschritte auf dem Gebiet der Rontgenstrahlen und der Bildgeb. Verfahren, 2014, 186(2): 157-165.

[8] Jung, T. and Kim, J. Y. Finite Element Structural Analysis of Self-Expandable Stent Deployment in a Curved Stenotic Artery. J. Mech. Sci. Technol., 2016, 30(7): 3143-3149.

[9] Dake, M. D., Alstine, W. G. V., Zhou, Q. and Ragheb, A. O. Polymer-Free Paclitaxel-Coated Zilver PTX Stents - Evaluation of Pharmacokinetics and Comparative Safety in Porcine Arteries. J. Vasc. Interv. Radiol., 2011, 22(5): 603-610.

[10] García, A., Peña, E. and Martínez, M. A. Influence of Geometrical Parameters on Radial Force During SelfExpanding Stent Deployment. Application for a Variable Radial Stiffness Stent. J. Mech. Behav. Biomed. Mater., 2012, 10: 166-175.

[11] Voûte, M. T., Hendriks, J. M., Laanen, J. H. H. V., Pattynama, P. M. T., Muhs, B. E., Poldermans, D. and Verhagen H. J. M. Radial Force Measurements in Carotid Stents: Influence of Stent Design and Length of the Lesion. J. Vasc. Interv. Radiol., 2011, 22(5): 661-666.

[12] Lin, P. H., Poi, M. J., Matos, J., Kougias, P., Bechara, C. and Changyi, C. Schwartz's Principles of Surgery. $10^{\text {th }}$ edition. New York City: McGraw-Hill Education. 2015.

[13] Woo, S. Y., Joh, J. H., Han, S. and Park, H. Prevalence and risk factors for atherosclerotic carotid stenosis and 
plaque. Medicine (Baltimore)., 2017, 96(4): e5999.

[14] Guccione, J. M., Kassab, G. S. and Ratcliffe, M. B. Computational Cardiovascular Mechanics Modelling and Applications in Heart Failure. $1^{\text {st }}$ edition. New York: Springer. 2010.

[15] Murphy, J. and Boyle, F. Predicting Neointimal Hyperplasia in Stented Arteries Using Time-Dependant Computational Fluid Dynamics: A Review. Comput. Biol. Med., 2010, 40(4): 408-418.

[16] Malek, A. M., Alper, S. L. and Izumo, S. Hemodynamic Shear Stress and Its Role in Atherosclerosis. Jama, 1999, 282(21): 2035-2042.

[17] Murphy, J. and Boyle, F. Comparing Stent Design Using Computational Fluid Dynamics to Predict Wall Shear Stress Based Parameters. Bioengineering in Ireland 15 Conference. January 30-31, 2009.

[18] LaDisa, J. F., Guler, I., Olson, L. E., Hettrick, D. A., Kersten, J. R., Warltier, D. C. and Pagel, P. S. ThreeDimensional Computational Fluid Dynamics Modeling of Alterations in Coronary Wall Shear Stress Produced by Stent Implantation. Ann. Biomed. Eng., 2003, 31(8): 972-980.

[19] Nandini, D., Schoephoerster, R. T. and Moore Jr, J. E. Comparison of Near-wall Hemodynamic Parameters in Stented Artery Models. J. Biomech. Eng., 2009, 131(6): 1-22.

[20] Balossino, R., Gervaso, F., Migliavacca, F. and Dubini, G. Effects of Different Stent Designs on Local Hemodynamics in Stented Arteries. J. Biomech., 2008, 41(5): 1053-1061.

[21] He, Y., Duraiswamy, N., Frank, A. O. and Moore, J. E. Blood Flow in Stented Arteries: A Parametric Comparison of Strut Design Patterns in Three Dimensions. J. Biomech. Eng., 2005, 127(4): 637-647.

[22] Murphy, J. B. and Boyle, F. J. A Numerical Methodology to Fully Elucidate the Altered Wall Shear Stress in a Stented Coronary Artery. Cardiovasc. Eng. Technol., 2010, 1(4): 256-268.

[23] Taib, I. Improvement of Haemodynamic Stent Strut Configuration for Patent Ductus Arteriosus through Computational Modelling. Ph.D. Universiti Teknologi Malaysia; 2016.

[24] Ulrich, K. T. and Eppinger, S. D. Product Design and Development. $5^{\text {th }}$ edition. Singapore: McGraw-Hill. 2012.

[25] Rabe, K., Franke, J. and Sievert, H. Practical Handbook of Advanced Interventional Cardiology: Tips and Tricks. $3^{\text {rd }}$ edition. Massachusetts: Blackwell Publishing. 2009.

[26] Azhim, A., Sakagami, K., Ueno, A., Kinouchi, Y. and Fukui, Y. Independent factors of Flow Velocity Indices in Common Carotid Artery. World Congress on Medical Physics and Biomedical Engineering. 2013. 39: 445448.

[27] Samijo, S. K., Willigers, J. M., Barkhuysen, R., Kitslaar, P. J., Reneman, R. S., Brands, P. J. and Hoeks A. P. Wall Shear Stress in the Human Common Carotid Artery as Function of Age and Gender. Cardiovasc. Res., 1998, 39(2): 515-522.

[28] Suess, T., Anderson, J., Danielson, L., Pohlson, K., Remund, T., Blears, E., Gent, S. and Kelly, P. Examination of Near-Wall Hemodynamic Parameters in The Renal Bridging Stent of Various Stent Graft Configurations for Repairing Visceral Branched Aortic Aneurysms. J. Vasc. Surg., 2016, 64(3): 788-796.

[29] Mut, F., Löhner, R., Chien, A., Tateshima, S., Viñuela, F., Putman, C. and Cebral, J. Computational Hemodynamics Framework for the Analysis of Cerebral Aneurysms. Int j Numer method biomed eng, 2011 27(6): 822-839.

[30] Ku, D. N., Giddens, D. P., Zarins, C. K. and Glagov, S. Pulsatile Flow and Atherosclerosis in the Human Carotid Bifurcation Positive Correlation between Plaque Location and Low Oscillating Shear Stress. Arter. Thromb Vasc Biol, 1985, 5(3): 293-302.

[31] Darlis, N. Improvement of spiral flow aortic cannula for cardiopulmonary bypass operation. Ph.D. Universiti Teknologi Malaysia; 2016.

[32] Youssefi, P., Gomez, A., He, T., Anderson, L., Bunce, N., Sharma, R., Figueroa, C. A. and Jahangiri, M. Patient-Specific Computational Fluid Dynamics - Assessment of Aortic Hemodynamics in a Spectrum of Aortic Valve Pathologies. J. Thorac. Cardiovasc. Surg., 2016, 153(1): 8-20.

[33] Hsiao, H. M., Lee, K. H., Liao, Y. C. and Cheng, Y. C. Hemodynamic Simulation of Intra-Stent Blood Flow. Procedia Eng., 2012, 36: 128-136.

[34] Frydrychowicz, A., Stalder, A. F., Russe, M. F., Bock, J., Bauer, S., Harloff, A., Langer, M., Hennig, J. and Markl, M. Three-dimensional analysis of segmental wall shear stress in the aorta by flow-sensitive fourdimensional-MRI. J. Magn. Reson. Imaging, 2009, 30(1): 77-84.

[35] Chaichana, T., Sun, Z. and Jewkes, J. Computation of hemodynamics in the left coronary artery with variable angulations. J. Biomech., 2011, 44(10): 1869-1878.

[36] Samuelson, R., Nair, P., Snyder, K., Frakes, D., Preul, M. C., Nakaji, P. and Spetzler, R. F. Fluid dynamic characterization of a novel branching anastomosis design. Int. Biomech., 2015, 2(1): 73-78.

[37] Gundert T. J., Dholakia, R., McMahon, J. D. and LaDisa, J. F. Computational Fluid Dynamics Evaluation of Equivalency in Hemodynamic Alterations Between Driver, Integrity, and Similar Stents Implanted into an Idealized Coronary Artery. J. Med. Device., 2013, 7(1): 11004.

[38] Lu, Y., Li, W., Oraifige, I. and Wang, W. Converging Parallel Plate Flow Chambers for Studies on the Effect of the Spatial Gradient of Wall Shear Stress on Endothelial Cells. J. Biosci. Med., 2014, 2(2): 50-56. 
[39] LaDisa, J. F., Olson, L. E., Guler, I., Hettrick, D. A., Audi, S. H., Kersten, J. R., Warltier, D. C. and Pagel, P. S. Stent design properties and deployment ratio influence indexes of wall shear stress : a three-dimensional computational fluid dynamics investigation within a normal artery. J Appl Physiol, 2004, 97: 424-430.

[40] Ahsaas, S. and Tiwari, S. Numerical Simulation of Blood Flow through Asymmetric and Symmetric Occlusion in Carotid Artery. Proceedings of the 3rd International Conference on Fluid Flow, Heat and Mass Transfer (FFHMT'16). May 2-3, 2016.

[41] Soulis, J. V., Lampri, O. P., Fytanidis, D. K. and Giannoglou, G. D. Relative residence time and oscillatory shear index of non-Newtonian flow models in aorta. 10th International Workshop on Biomedical Engineering. October 5-7, 2011.

[42] Mahmoud, M. M., Serbanovic-Cavic, J., Feng, S., Souilhol, C., Xing, R., Hsiao, S., Mammoto, A., Chen, J., Ariaans, M., Francis, S. E., Van der Heiden, K., Ridger, V. and Evans, P. C. Shear stress induces endothelialto-mesenchymal transition via the transcription factor Snail. Sci. Rep., 2017, 7(1): 3375.

[43] Miura, Y., Ishida, F., Umeda, Y., Tanemura, H., Suzuki, H., Matsushima, S., Shimosaka, S. and Taki, W. Low wall shear stress is independently associated with the rupture status of middle cerebral artery aneurysms. Stroke, 2013, 44(2): 519-521.

[44] Eshtehardi, P., Brown, A. J., Bhargava, A., Costopoulus, C., Hung, O. Y., Corban, M. T., Hosseini, H., Gogas, B. D., Giddens, D. P. and Samady, H. High wall shear stress and high-risk plaque : an emerging concept. Int. J. Cardiovasc. Imaging, 2017, 33(7): 1089-1099.

[45] Chistiakov, D. A., Orekhov, A. N. and Bobryshev, Y. V. Effects of shear stress on endothelial cells : go with the flow. Acta Physiol, 2016, 219(2): 382-408.

[46] Geoghegan, P. H., Jermy, M. C. and Nobes, D. S. A PIV Comparison of the Flow Field and Wall Shear Stress in Rigid and Compliant Models of Healthy Carotid Arteries. J. Mech. Med. Biol., 2017, 17(4): 1-16.

[47] Timmins, L. H., Molony, D. S., Eshtehardi, P., McDaniel, M. C., Oshinski, J. N., Giddens, D. P. and Samady, $\mathrm{H}$. Oscillatory wall shear stress is a dominant flow characteristic affecting lesion progression patterns and plaque vulnerability in patients with coronary artery disease. J. R. Soc. Interface, 2017, 14: 20160972.

[48] Saw, S. N., Dawn, C., Biswas, A., Mattar, C. N. Z. and Yap, C. H. Characterization of the in vivo wall shear stress environment of human fetus umbilical arteries and veins. Biomech. Model. Mechanobiol., 2016, 16(1): 197-211.

[49] John, L., Pustějovská, P. and Steinbach, O. On the influence of the wall shear stress vector form on hemodynamic indicators. Comput Vis. Sci, 2017, 18(4-5): 113-122.

[50] Mccormick, M. E., Manduchi, E., Witschey, W. R. T., Gorman, R. C., Gorman, J. H., Jiang, Y. Z., Stoeckert, C. J., Barker, A. J., Yoon, S., arkl, M. and Davies, P. F. Spatial phenotyping of the endocardial endothelium as a function of intracardiac hemodynamic shear stress. J. Biomech., 2016, 50: 11-19.

[51] Kanokjaruvijit, K., Donprai-on, T., Phanthura, N., Noidet, P. and Siripokharattana, J. Wall shear stress and velocity distributions in different types of stenotic bifurcations. J. Mech. Sci. Technol., 2017, 31(5): 2339_ 2349.

[52] Sano, T., Ishida, F., Tsuji, M., Furukawa, K., Shimosaka, S. and Suzuki, H. Hemodynamic differences between ruptured and unruptured cerebral aneurysms simultaneously existing in the same location: two case reports and proposal of a novel parameter oscillatory velocity index. World Neurosurg., 2017, 98: 868.e5868.e10.

[53] Geers, A. J., Morales, H. G., Larrabide, I., Butakoff, C., Bijlenga, P. and Frangi, A. F. Wall shear stress at the initiation site of cerebral aneurysms Biomech. Model. Mechanobiol., 2017, 16(1): 97-115.

[54] Bergersen, A. W. Investigating the Link Between Patient-specific Morphology and Hemodynamics: Implications for Aneurism Initiation? University of Oslo; 2016.

[55] Soulis, J. V., Fytanidis, D. K., Seralidou, K. V. and Giannoglou, G. D. Wall shear stress oscillation and its gradient in the normal left coronary artery tree bifurcations. Hippokratia, 2014, 18(1): 12-16.

[56] Himeno, M., Noda, S., Fukasaku, K., Himeno, R. and Tadano, S. A method to evaluate relevance of hemodynamic factors to artery bifurcation shapes using computational fluid dynamics and genetic algorithms. Mech. Eng. J., 2017, 4(3): 1-15.

[57] Terashima, M., Miura, Y., Ishida, F., Toma, N., Araki, T., Shimodaka, S., Kanamaru, K. and Suzuki, H. Onestage Stent-assisted Coil Embolization for Rupture-side-unknown Bilateral Vertebral Artery Dissecting Aneurysms in an Acute Stage: A Case Report. NMC Case Rep. J., 2018, 5: 45-49.

[58] DePaola, N., Gimbrone, M. A. J., Davies, P. F. and Dewey, C. F. J. Vascular Endothelium Responds to Fluid Shear Stress Gradients. Arterioscler. Thromb., 1992, 12: 1254-1257.

[59] Filipović, N., Nikolić, D., Saveljić, I., Exarchos, T. and Parodi, O. Experimental Testing and Numerical Modelling of Stents in the Coronary Arteries. Contemp. Mater., 2016, 2(7): 99-108.

[60] Tanaka, K., Ishida, F., Kawamura, K., Yamamoto, H., Horikawa, D. D., Kishimoto, T., Tsuji, M., Tanemura, H. and Shimosaka, S. Hemodynamic Assessment of Cerebral Aneurysms using Computational Fluid Dynamics (CFD) Involving the Establishment of Non-Newtonian Fluid Properties. J. Neuroendovascular Ther., 2018, 12(6): 1-10. 
[61] Asiruwa, J. J. Assessing the Near-Wall Hemodynamics in the Left Coronary Artery Using CFD. South Dakota State University; 2017.

[62] Zhao, J.-L., Jia, L., Wang, X.-B., Zhang, L.-L., Rong, W.-L., Jiang, J.-W. and Li, M.-H. Effects of adjustable impinging flow on the vascular endothelial cell layer in a modified T chamber. Int J Clin Exp Med, 2017, 10(3): 5068-5074.

[63] Machi, P., Ouared, R., Brina, O., Bouillot, P., Yilmaz, H., Vargas, M. I., Bijlenga, P., Lovblad, K. O. and Kulcsár, Z. Hemodynamics of Focal Versus Global Growth of Small Cerebral Aneurysms. Clin Neuroradiol, 2017.

[64] Liu, Z., Cai, Y., Chen, G., Lu, G. and Li, Z. Anatomical Variations in Circle of Willis and Intracranial Aneurysm Formation. MCN, 2017, 15(1): 19-31.

[65] Dai, Y., Lv, P., Javadzadegan, A., Tang, X., Qian, Y. and Lin, J. Hemodynamic analysis of carotid artery after endarterectomy: a preliminary and quantitative imaging study based on computational fluid dynamics and magnetic resonance angiography resonance angiography. Quant Imaging Med Surg, 2018, 8(4): 399-409.

[66] Avery, M. Can Mesenchymal Stem Cells Inhibit the Formation of Saccular Aneurysms? University of Calgary; 2017.

[67] Lauric, A., Greim-Kuczewski, K., Antonov, A., Dardik, G., Magida, J. K., Hippelheuser, J. E., Kono, K. and Malek, A. M. Proximal Parent Vessel Tapering is Associated With Aneurysm at the Middle Cerebral Artery Bifurcation. Neurosurgery, 2018.

[68] Tsukui, H., Shinke, M., Park, Y. K. and Yamazaki, K. Longer coronary anastomosis provides lower energy loss in coronary artery bypass grafting. Heart Vessels, 2017, 32(1): 83-89.

[69] Pike, D., Shiu, Y.-T., Somarathna, M., Guo, L., Isayeva, T., Totenhagen, J. and Lee, T. High resolution hemodynamic profiling of murine arteriovenous fistula using magnetic resonance imaging and computational fluid dynamics. Theor. Biol. Med. Model., 2017, 14(5): 1-17.

[70] Yang, L., Yin, A. and Liu, W. Variation of flow rate and angle of injected venous needle on influencing intimal hyperplasia at the venous anastomosis of the hemodialysis graft. Australas. Phys. Eng. Sci. Med., 2017, 40(1): 239-248.

[71] Suzuki, D., Funamoto, K., Sugiyama, S., Hayase, T., Miyauchi, S. and Tominaga, T. Effects of upstream bifurcation and bend on the blood flow in a cerebral aneurysm. J. Biomech. Sci. Eng., 2017, 12(4): 1-11.

[72] Gayathri, K. and Shailendhra, K. Mathematical investigation of aetiology and pathogenesis of atherosclerosis in human arteries. Int. J. Bioinforma. Res. Appl., 2018, 14(1/2): 3-28.

[73] Chen, Y. Zhang, P., Deng, X., Fan, Y., Xing, Y. and Xing, N. Improvement of hemodynamic performance using novel helical flow vena cava filter design. Scientific Reports, 2017.

[74] Asiruwa, J. J., Propst, A. M. and Gent, S. P. Hemodynamics Study of Different Take-off Angles of the Left Coronary Artery. Design of Medical Devices Conference. April 10-13, 2017.

[75] Tran, J. S., Schiavazzi, D. E., Ramachandra, A. B., Kahn, A. M. and Marsden, A. L. Automated Tuning for Parameter Identification and Uncertainty Quantification in Multi-scale Coronary Simulations. Comput. Fluids, 2016, 142: 128-138.

[76] Xu, H., Piccinelli, M., Leshnower, B. G., Lefieux, A., Taylor, W. R. and Veneziani, A. Coupled Morphological - Hemodynamic Computational Analysis of Type B Aortic Dissection : A Longitudinal Study. Ann. Biomed. Eng., 2018, 46(7): 927-939.

[77] Riccardello, G. J., Shastri, D. N., Changa, A. R., Thomas, K. G., Roman, M. Prestigiacomo, C. J. and Gandhi C. D. Influence of Relative Residence Time on Side-Wall Aneurysm Inception," Neurosurgery, 2017.

[78] Berg, P. and Beuing, O. Multiple intracranial aneurysms : a direct hemodynamic comparison between ruptured and unruptured vessel malformations. Int. J. Comput. Assist. Radiol. Surg., 2017, 13(1): 83-93.

[79] Van de Velde, L., Donselaar, E. J., Groot Jebbink, E., Boersen, J. T., Lajoinie, G. P. R., de Vries, J. P. M., Zeebregts, C. J., Versluis, M. and Rejinen, M. M. P. J. Partial renal coverage in endovascular aneurysm repair causes unfavorable renal flow patterns in an infrarenal aneurysm model. J. Vasc. Surg., 2018, 67(5): 15851594.

[80] Bit, A. and Chattopadhay, H. Acute Aneurysm is more Critical than Acute Stenoses in Blood Vessels: a Numerical Investigation Using Stress Markers. BioNanoSci., 2018, 8(1): 329-336.

[81] Asiruwa, J. J., Propst, A. M. and Gent, S. P. Assessing Near-Wall Hemodynamics of Blood Flow in the Left Anterior Descending Segment of the left Coronary Artery using Computational Fluid Dynamics. ASME 2017 International Mechanical Engineering Congress and Exposition. November 3-9, 2017.

[82] Shamloo, A., Nejad, M. A. and Saeedi, M. Fluid-structure interaction simulation of a cerebral aneurysm: effects of endovascular coiling treatment and aneurysm wall thickening. J. Mech. Behav. Biomed. Mater., 2017, 74: 72-83.

[83] Barber, T. Wall shear stress and near-wall flows in the stenosed femoral artery. Comput. Methods Biomech. Biomed. Engin., 2017, 20(10): 1048-1055.

[84] Brindise, M. C., Chiastra, C., Burzotta, F., Migliavacca, F. and Vlachos, P. P. Hemodynamics of Stent Implantation Procedures in Coronary Bifurcations: an In Vitro study. Ann Biomed Eng., 2017, 45(3):542-553. 
[85] Pinto, S. I. S., Castro, C. F., Sousa, L. C. and Campos, J. B. L. M. Numerical Study of Atherogenesis Risk Associated to Different Stenotic Arteries. 7th International Conference on Mechanics and MAterials in Design. June 11-15 2017.

[86] Varble, N., Rajabzadeh-Oghaz, H., Wang, J., Siddiqui, A., Meng, H. and Mowla, A. Differences in Morphologic and Hemodynamic Characteristics for 'PHASES-Based' Intracranial Aneurysm Locations. Am. J. Neuroradiol., 2017, 38(11): 2105-2110.

[87] Zhang, X., Lv, N., Wang, C., Cao, W., Liu, J. and Huang, Q. Late recurrence of a completely occluded large intracranial aneurysm treated with a Tubridge flow diverter. Journal of NeuroIntervential Surgery, 2016, 9(2).

[88] Arzani, A., Shadden, S. C., Gambaruto, A. M. and Chen, G. Wall shear stress exposure time : a Lagrangian measure of near-wall stagnation and concentration in cardiovascular flows. Biomech. Model. Mechanobiol., 2017, 16(3): 787-803.

[89] Xiong, J., Hu, Z., Zhang, H., Xu, H., Chen, D. and Guo, W. Successful use of retrograde branched extension limb assembling technique in endovascular repair of pararenal abdominal aortic aneurysm. J. Vasc. Surg. Cases Innov. Tech., 2017, 3(2): 90-94.

[90] Chen, Z., Yu, H., Shi, Y., Zhu, M., Wang, Y., Hu, X., Zhang, Y., Chang, Y., Xu, M. and Gao, W. Vascular Remodelling Relates to an Elevated Oscillatory Shear Index and Relative Residence Time in Spontaneously Hypertensive Rats. Sci. Rep., 2017, 7(1): 2007.

[91] Tzirakis, K., Kamarianakis, Y., Metaxa, E., Kontopodis, N., Ioannou, C. V. and Papaharilaou, Y. A robust approach for exploring hemodynamics and thrombus growth associations in abdominal aortic aneurysms. Med. Biol. Eng. Comput., 2017, 55(8): 1493-1506.

[92] Carrascal, P. G., Garcia, J. G., Pallares, Ruiz, F. C. and Martin, F. J. M. Numerical Study of Blood Clots Influence on the Flow Pattern and Platelet Activation on a Stented Bifurcation Model. Ann. Biomed. Eng., 2016, 45(5): 1279-1291.

[93] Himburg, H. A., Grzybowski, D. M., Hazel, A. L., LaMack, J. A., Li, X. M. and Friedman, M. H. Spatial comparison between wall shear stress measures and porcine arterial endothelial permeability. Am J Physiol Hear. Circ Physiol, 2004, 286: H1916-H1922.

[94] Duraiswamy, N., Cesar, J. M., Schoephoerster, R. T. and Moore, J. E. Effects of stent geometry on local flow dynamics and resulting platelet deposition in an in vitro model. Biorheology, 2008, 45: 547-561.

[95] Martin, D., Murphy, E. and Boyle, F. Computational Fluid Dynamics Analysis of Balloon-Expandable Coronary Stents : Influence of Stent and Vessel Deformation coronary stents : Influence of stent and vessel deformation. Med Eng Phys, 2014, 36(8): 1047-1056.

[96] De Santis, G., Trachet, B., Conti, M., De Beule, M., Morbiducci, U., Mortier, P., Segers, P., Verdonck, P. and Verhegghe, B. A Computational Study of the Hemodynamic Impact of Open- Versus Closed-Cell Stent Design in Carotid Artery Stenting. Artif. Organs, 2013, 37(7): E96-E106.

[97] M.S.A. Paisal, S.F.S Adnan, I. Taib, A.E Ismail, M.K Abdullah, N. Nordin, S.M Seri and N. Darlis. Flow Characteristics Near to Stent Strut Configurations on Femoropopliteal Artery. IOP Conference Series: Materials Science and Engineering, 2017, 226(1), 012147.

[98] B.A Mohd Atan, A.E Ismail, I. Taib and Z. Lazim. A review on fracture prevention of stent in femoropopliteal artery. IOP Conference Series: Materials Science and Engineering, 2017, 166(1), 012006.

[99] M.S Amir Paisal, I. Taib and A.E Ismail. Computational Analysis on Stent Geometries in Carotid Artery: A Review. IOP Conference Series: Materials Science and Engineering, 2017, 166(1) vol. 166, 012003.

[100] Z. Lazim, A.E Ismail, I. Taib and B.A Mohd Atan. A review of stent's failure on patent ductus arteriosus. IOP Conference Series: Materials Science and Engineering, 2017, 166(1), 012007.

[101] Asrizan Kaha, Ishkrizat Taib, Muhammad Sufyan Amir Paisal, Ahmad Mubarak Tajul Arifin, Al Emran Ismail, Norzelawati Asmuin, Reazul Haq Abdul Haq, Surapong Chatpun, Takahisa Yamamoto, and Kahar Osman. Lumped Parameter Modelling in Femoral Popliteal Artery for Normal and Severe Conditions. International Journal of Integrated Engineering: Special issue 2018: Mechanical Engineering, 2018, 10(5):193-203.

[102] A. Hamdan, F. Mustapha, K.A Ahmad, A.S Mohd Rafie, M.R Ishak, and A.E Ismail. The Effect of Customized Woven and Stacked Layer Orientation on Tensile and Flexural Properties of Woven Kenaf Fibre Reinforced Epoxy Composites. International Journal of Polymer Science, 2016, 2016, 6514041.

[103] A.E Ismail, M.A Hassan. Low velocity impact on woven kenaf fiber reinforced composites. Applied Mechanics and Materials, 2014, 629:503-506.

[104] A.E Ismail, A.K Ariffin, S. Abdullah, M.J Ghazali. Finite element analysis of J-integral for surface cracks in round bars under combined mode I loading. International Journal of Integrated Engineering, 2017, 9(2):1-8. 